NBER WORKING PAPER SERIES

\title{
THE EFFECT OF CHILD HEALTH INSURANCE ACCESS ON SCHOOLING: EVIDENCE FROM PUBLIC INSURANCE EXPANSIONS
}

\author{
Sarah Cohodes \\ Daniel Grossman \\ Samuel Kleiner \\ Michael F. Lovenheim \\ Working Paper 20178 \\ http://www.nber.org/papers/w20178 \\ NATIONAL BUREAU OF ECONOMIC RESEARCH \\ 1050 Massachusetts Avenue \\ Cambridge, MA 02138 \\ May 2014
}

We are grateful to Tal Gross, Kosali Simon and Diane Schanzenbach for helpful comments and guidance on all simulated eligibility calculations. We also thank seminar participants at Cornell University, Harvard University, the 2014 American Economic Association Annual Meeting as well as David Autor, Amitabh Chandra, Larry Katz and Aaron Yelowitz for helpful feedback on earlier versions of this work. This paper represents a combination of two prior working papers: "The Impact of Medicaid Expansion for Children on their Educational Attainment" by Sarah Cohodes and "The Effect of Health Care Access on Schooling: Evidence from Public Insurance Expansions" by Samuel Kleiner, Michael Lovenheim and Daniel Grossman. Cohodes gratefully acknowledges support from a Harvard University grant from the Multidisciplinary Program in Inequality and Social Policy. The views expressed herein are those of the authors and do not necessarily reflect the views of the National Bureau of Economic Research.

NBER working papers are circulated for discussion and comment purposes. They have not been peerreviewed or been subject to the review by the NBER Board of Directors that accompanies official NBER publications.

(C) 2014 by Sarah Cohodes, Daniel Grossman, Samuel Kleiner, and Michael F. Lovenheim. All rights reserved. Short sections of text, not to exceed two paragraphs, may be quoted without explicit permission provided that full credit, including (C) notice, is given to the source. 
The Effect of Child Health Insurance Access on Schooling: Evidence from Public Insurance Expansions

Sarah Cohodes, Daniel Grossman, Samuel Kleiner, and Michael F. Lovenheim

NBER Working Paper No. 20178

May 2014, Revised October 2014

JEL No. H51,H52,I13,I21,I28

\section{$\underline{\text { ABSTRACT }}$}

Public health insurance programs comprise a large share of federal and state government expenditures. Although a sizable literature analyzes the effects of these programs on health care utilization and health outcomes, little prior work has examined the long-term effects and resultant health improvements on important outcomes, such as educational attainment. We contribute to filling this gap in the literature by examining the effects of the public insurance expansions among children in the 1980s and 1990s on their future educational attainment. Our findings indicate that expanding health insurance coverage for low-income children increases the rate of high school completion and college completion. These estimates are robust to only using federal Medicaid expansions, and mostly are due to expansions that occur when the children are older (i.e., not newborns). We present suggestive evidence that better health is one of the mechanisms driving our results by showing that Medicaid eligibility when young translates into better teen health. Overall, our results indicate that the long-run benefits of public health insurance are substantial.

Sarah Cohodes

John F. Kennedy School of Government

Harvard University

79 JFK Street

Cambridge, MA 02138

cohodes@fas.harvard.edu

Daniel Grossman

MVR Hall, Dept. of PAM

Cornell University

Ithaca NY 14853

dan.s.grossman@gmail.com
Samuel Kleiner

Cornell University

College of Human Ecology

108 Martha Van Rensselaer Hall

Ithaca, NY 14853

and NBER

skleiner@cornell.edu

Michael F. Lovenheim

Department of Policy Analysis and Management Cornell University

102 Martha Van Rensselaer Hall

Ithaca, NY 14853

and NBER

mf155@cornell.edu 


\section{Introduction}

Whether and how to provide access to affordable healthcare for low-income Americans has become a central policy issue in the US, driven in part by the large and persistent health disparities that exist across the socioeconomic spectrum. The importance of this issue is underscored by the intense debate surrounding the passage and implementation of the 2010 Affordable Care Act (ACA), one of the largest expansions of public health insurance in US history. A core component of the ACA was to further expand eligibility for Medicaid, which is the primary method through which the government provides affordable health insurance to lowincome families. Since its inception in 1965, Medicaid has gone through repeated expansions that have greatly expanded the scope of the program as well as the public sector's role in health insurance provision. As a result, over $50 \%$ of children in the United States currently are eligible for publicly-provided health insurance through this program, ${ }^{2}$ and health insurance coverage is high amongst this population (DeNavas-Walt et al., 2013).

The expansions that generated this high level of coverage were expensive. In 2012, total state and federal spending on Medicaid was $\$ 415.2$ billion (Henry J. Kaiser Family Foundation, 2014), which makes it the largest government program that targets low-income Americans. ${ }^{3}$ The substantial public funds devoted to providing health insurance to low-income children, as well as recent debates over the value of such insurance that surrounded the passage of the ACA, highlight the importance of understanding what benefits, if any, accrue to individuals due to health insurance access when they are young.

\footnotetext{
${ }^{2}$ Throughout this paper, we refer to "public health insurance" and Medicaid synonymously. Publicly-provided health insurance also includes State Children's Health Insurance Plans (SCHIP). Medicare, however, is not included in our definition of public health insurance for purposes of this paper.

${ }^{3}$ As a point of reference, total expenditures on food stamps (SNAP) in 2012 were $\$ 78.4$ billion, and spending on Temporary Aid for Needy Families (TANF) was \$31.4 billion. Total Medicare expenditures were $\$ 536$ billion, which highlights that the Medicare and Medicaid/SCHIP programs are of roughly similar size.
} 
The effect of Medicaid expansions on access to healthcare and on subsequent child health has been studied extensively, (e.g., Currie and Gruber, 1996a, 1996b; Moss and Carver, 1998; Baldwin et al., 1998; Cutler and Gruber, 1996, LoSasso and Buchmueller, 2004; Gruber and Simon, 2008), typically showing that Medicaid expansions increase access to healthcare, decrease infant mortality, and improve childhood health. Furthermore, these expansions and Medicaid access more generally have been linked to a lower likelihood of bankruptcy and to less medical debt (Gross and Notowidigdo, 2011; Finkelstein et al., 2012). If Medicaid leads to better health outcomes among children and to more stable finances among low-income households, as is suggested by prior research, Medicaid expansions could lead to long-run benefits for affected children. Given the persistently high returns to human capital investments (e.g., Autor, Katz and Kearney, 2008) as well as human capital models that suggest childhood health and family resources should both positively influence educational attainment, examining the effects of Medicaid expansions on long-run educational attainment is of considerable policy interest.

In this paper, we provide the first US-based evidence in the literature on how expanding health insurance for children influences their eventual educational attainment. ${ }^{4}$ Similar to prior work on Medicaid, we exploit the expansions of Medicaid and the State Children's Health Insurance Program (SCHIP) that took place in the 1980s and 1990s to examine how the educational attainment of these children was affected by access to these programs. We use data on 22-29 year olds born between 1980 and 1990 from the 2005-2012 American Community Survey (ACS) that allow us to match each respondent to his or her state of birth. We then use

\footnotetext{
${ }^{4}$ Two prior studies have examined the role of public health insurance on educational attainment in the developing world (Alcaraz et al., 2013; Chen and Jin, 2012), however it is doubtful that these results can be generalized to the United States or to other industrialized nations.
} 
data from the March Current Population Survey (CPS) to calculate Medicaid eligibility by age, state, year and race that we link to our ACS sample.

With these data, we follow the method of simulated instrumental variables pioneered by Currie and Gruber (1996a, 1996b) and Cutler and Gruber (1996), in which we use Medicaid eligibility of a fixed population in each age, state, year and race as an instrument for actual eligibility. This IV approach accounts for the fact that the composition of a state may be endogenous to Medicaid eligibility rules. By using a fixed sample to calculate eligibility, the model is identified using eligibility rule changes only. The underlying identification assumption for our purposes is that Medicaid rules are not changing due to unobserved cross-cohort trends in educational attainment. A large body of prior work has established the credibility of this assumption in terms of health, fertility and family bankruptcy (Currie and Gruber, 1996a; DeLeire et al., 2011; Gross and Notowidigdo, 2011). We extend this literature by implementing a series of robustness checks, including using only federal Medicaid variation that cannot be affected by state-level choices, to further support the validity of this methodology.

The main contribution of this paper to the literature is to demonstrate the effect of health insurance access among both young and school-age children on their long-run educational attainment. While there is a sizable body of research demonstrating a link between fetal health as well as the provision of fetal healthcare services on future educational outcomes (e.g., Figlio et al., 2013; Levine and Schanzenbach, 2009; Currie and Gruber, 1996b), the effect of children’s access to healthcare services on their educational attainment has not been studied previously. ${ }^{5}$

\footnotetext{
${ }^{5}$ Currie, Decker and Lin (2008) present suggestive evidence that exposure to Medicaid expansions when young lead to better health in adolescence, which suggests there could be an effect on educational attainment as well. In a related study, Brown, Kowalski and Lurie (2014) use IRS tax data to show that the eligibility expansions in the 1980s led to higher earnings by the time individuals reached the age of 31. Their work does not examine educational attainment, but their results and ours strongly complement one another.
} 
From a policy perspective, this is an important group to consider because of the large amount spent on providing health insurance to non-newborn children. Furthermore, socioeconomic disparities in educational outcomes begin at young ages and largely persist throughout the lifecycle (Carneiro and Heckman, 2002; Todd and Wolpin, 2007). Thus, it is critical to understand whether reducing health insurance disparities across the socioeconomic distribution among children can be useful as a means to close these persistent educational gaps that are present in later years.

We find consistent evidence that Medicaid exposure when young increases later educational attainment. A 10 percentage point increase in average Medicaid eligibility between the ages of 0-17 decreases the high school dropout rate by $0.4-0.5$ of a percentage point, has a small and typically insignificant effect on college enrollment, and increases the four-year college attainment rate (i.e., BA receipt) by 0.6-1.0 percentage point. These estimates translate into declines in high school non-completion of about 4.0-5.9\% and increases in BA attainment of about $2.3 \%-3.0 \%$ relative to the sample means. In separate estimates by race, we find that the high school completion effects are localized to nonwhites, while the college completion rate impacts are largest among white children.

Another important contribution of this analysis is to examine whether it is sufficient for a child to be treated at birth or whether there are returns to expanding eligibility amongst older, largely school-age children. Prior work in this area has focused more on eligibility at birth than on the effects of eligibility at older ages (Levine and Schanzenbach, 2009; Currie and Gruber, 1996b). ${ }^{6}$ We provide some of the first estimates in this literature on heterogeneity by age at the time of expansion. While we do not find strong age patterns in the data, we see evidence that

\footnotetext{
${ }^{6}$ Currie and Gruber (1996a) examine effects of Medicaid expansions on child mortality for children 1-14, but they do not break out the effects by child age at expansion.
} 
Medicaid expansions at older ages have effects on educational attainment. That is, Medicaid expansions to slightly older, mostly school-age children increase educational attainment, not just eligibility expansions at birth. ${ }^{7}$

As a means to understand a central mechanism through which these effects operate, we examine the impact of Medicaid eligibility when young on teen health. Using data from the Youth Risk Behavior Surveillance System (YRBSS), we show suggestive evidence that Medicaid eligibility between age 0 and one's age at the time of the survey has sizable positive effects on a range of health outcomes. For example, an increase in Medicaid eligibility throughout one’s youth reduces risky sexual activity, body mass index (BMI), drinking, and smoking cigarettes or marijuana. Furthermore, Medicaid eligibility decreases the number of reported mental health issues, and students are less likely to report having an eating disorder. While these estimates typically are not statistically significantly different from zero at conventional levels, they provide support for the idea that better health is an important mechanism that drives at least part of the increased educational attainment we document.

Overall, our results point to large effects of Medicaid expansions for children on their eventual educational attainment. These effects are particularly important because lower-income families are most affected by Medicaid and SCHIP expansions, and it is children from these families that have exhibited the most sluggish growth in educational attainment over the past 30 years (Bailey and Dynarski, 2011). Our estimates suggest that the long-run returns to providing health insurance access to children are larger than just the short-run gains in health status, and

\footnotetext{
${ }^{7}$ The effect of Medicaid eligibility at birth could be biased downward due to the fact that Medicaid reduces infant mortality (Currie and Gruber, 1996b). Any resulting compositional changes in birth cohorts likely would lead to a reduction in long-run outcomes, all else equal. To the extent Medicaid changes the composition of births and/or of older children through reduced mortality, this should attenuate our estimates. However, infant and child mortality rates are sufficiently low in the US that any such attenuation is probably very small.
} 
that part of the return to these expansions is a potential reduction in inequality and higher economic growth that stems from the creation of a more skilled workforce.

The rest of this paper is organized as follows: Section 2 describes the public health expansions we use in our analysis, and Section 3 reviews the literature on the effects of health insurance on health and family finances as well as the literature examining the links between health, family resources and educational outcomes. Section 4 provides a description of the data. We outline our empirical strategy and detail our results in Sections 5 and 6, respectively, before concluding in Section 7.

\section{Medicaid and Public Health Care Expansions for Children}

The Medicaid program was introduced in 1965 and phased in mostly over the late 1960s as a health insurance component for state-based cash welfare programs that targeted low-income, single-parent families. Beginning in the mid-1980s, the Medicaid program was slowly separated from cash welfare, first by extending benefits to low-income children in two-parent families and then by raising the income eligibility thresholds for two groups: children and pregnant women (Gruber, 2003; Gruber and Simon, 2008). ${ }^{8}$ Thus, since the 1980s, Medicaid has been expanded to many low-income families who did not previously qualify due to their income levels, family composition and/or labor force participation. As a result of these expansions, by the mid-1990s, most children in America below the poverty line, and all young children below 133\% of the poverty line, were eligible for Medicaid. In certain states, their parents were as well.

Importantly, for most of these expansions, states could choose to implement the expansion based on their own eligibility preferences. By the early 1990's, states were required to cover all children below 100\% of the poverty line, and children under age 6 below 133\% of the

\footnotetext{
${ }^{8}$ For more details on Medicaid expansions, see Currie and Gruber (1996a), Gruber (2003), and Gruber and Simon (2008).
} 
poverty line. Many states opted to provide more generous coverage, however, for which the federal government would provide matching funds up to a certain threshold. In 1997, Congress passed the State Children's Health Insurance Plan (SCHIP), which was one of the largest expansions of public health insurance to date. SCHIP provided matching funds to states to expand coverage to children from households with incomes below $200 \%$ of the poverty line. Prior to SCHIP, states were permitted to cover children up to $200 \%$ of the poverty line, but, without federal matching funds, very few states did so.

In this paper, we exploit these expansions in Medicaid generosity in the 1980s and 1990s that were phased in at different times, and with different generosity levels across states, to identify the effect of Medicaid eligibility on long-run educational attainment. Thus, we use both state-level variation, which assumes the timing of state eligibility changes is exogenous with respect to underlying trends in educational attainment of residents, and federal variation to explicitly test the robustness of our estimates to the assumption that the state Medicaid variation is exogenous.

\section{Previous Literature}

The effect of Medicaid eligibility on education will flow through two main potential channels: better health due to Medicaid take-up, as well as higher household resources stemming from the insurance protection provided by Medicaid. This paper thus relates to the large literature examining the effect of Medicaid on health care utilization, health outcomes and household finances, as well as the literature linking health and family resource changes to educational outcomes. Below, we discuss both sets of research in turn.

3.1 Effects of Medicaid Expansions on Utilization, Health Outcomes and Family Finances 
Much prior research has documented the effects of Medicaid expansions on both the use of medical care and health status. In their examination of the effects of health insurance on utilization, Buchmueller et al. (2005) provide a detailed survey of this literature, noting that economic theory predicts that health insurance coverage induces greater medical care utilization by reducing the cost of care to patients (Phelps, 1997). Consistent with this prediction, studies of state-based Medicaid and federal expansions of coverage show that these programs lead to increases in health care use on both extensive and intensive margins. These effects are observed both among children and adults (e.g. Currie and Gruber, 1996a, 1996b; Currie, 2000; Kaestner et al., 2000; Kaestner et al., 2001; Almeida, Dubay, and Ko, 2001; Banthin and Selden, 2003; Dafny and Gruber, 2005). As noted by Levy and Meltzer (2008), while health insurance increases the quantity of care consumed, the effects of coverage will vary based on the availability of providers and efficacy of the medical care consumed as a result of increased coverage. While their review suggests that health insurance improves the health of infants and children (with little conclusive evidence shown for non-elderly adults), Finkelstein et al. (2012) present evidence that the expansion of public insurance improves both physical and mental health for adults as well.

Recent work also has suggested that public health insurance successfully shelters lowincome families from financial risk associated with negative health shocks. Gross and Notowidigdo (2011) show that families exposed to Medicaid expansions are less likely to declare bankruptcy, while the estimates of Dave et al. (2013) indicate that Medicaid eligibility was associated with a decrease in the employment probability of women who recently gave birth. In their study of the randomized Medicaid experiment in Oregon, Finkelstein et al. (2012) find that 
obtaining access to public health insurance reduces the amount of out-of-pocket medical expenditures as well as medical debt.

\subsection{Effects of Health and Family Resources on Educational Attainment}

How are such changes in child health and family finances from Medicaid expansions predicted to affect educational attainment? A sizable literature dating back to the seminal contribution of Grossman (1972) examines the effect of education on future health, ${ }^{9}$ but much less work has been done estimating the effect of health in childhood on educational achievement and attainment. Existing research has documented that better fetal health translates into increased educational outcomes. These studies testing the "fetal origins" hypothesis overwhelmingly show that health interventions and shocks among pregnant women, as well as differences in measurable health at birth, have long-run consequences for cognitive ability, educational outcomes of children, and adult health (e.g., Miller and Wherry, 2014; Figlio et al., 2013; Almond and Mazumder, 2011; Almond, Edlund and Palme, 2009; Almond, 2006; Black, Devereaux and Salvanes, 2007; Oreopoulos et al., 2008; Royer, 2009).

Despite the evidence linking fetal health to long-run outcomes, little research exists examining how childhood health after birth impacts such outcomes. Currie et al. (2010) find that children with health problems in early childhood have poorer long-run health, a higher likelihood of being on social assistance, and lower educational outcomes. Case, Fertig and Paxson (2005) and Case, Lubotsky and Paxson (2002) both show that worse health in childhood is negatively associated with long-run outcomes, such as health, educational attainment, and labor market outcomes. Historical evidence also suggests such a link exists: hookworm eradication led to

\footnotetext{
${ }^{9}$ There currently is very mixed evidence on whether education affects long-run health outcomes (e.g., Adams et al., 2003; Cutler and Lleras Muney, 2006; Grossman, 2004; Clark and Royer, 2013), with much heterogeneity in terms of the credibility of the identification strategies used, the time periods and countries studied, and the education levels examined.
} 
more school attendance and literacy gains in the US south in the early 1900's (Bleakley 2007), and malaria eradication efforts resulted in small gains in income for cohorts whose regions were treated before other cohorts (Bleakley 2010). ${ }^{10}$

Cox and Reback (2013) as well as Lovenheim, Reback and Wedenoja (2013) examine the effect of health care access on educational attainment using the rollout of school-based health centers in the US. The former study finds that center openings lead to high attendance rates, while the latter shows they cause lower teen birth rates but do not affect high school dropout rates. The students treated by these centers are typically in high school, so the differences between these estimates and the large effects of health found by researchers examining younger children may potentially be due to heterogeneity in the effects of health at different times during childhood.

Another main channel through which Medicaid can influence educational attainment is through its effect on family resources. Several recent studies attempt to isolate the causal impact of additional funds on educational achievement. Dahl and Lochner (2012) use the Earned Income Tax Credit (EITC) as an instrument for unexpected income changes and find that an additional $\$ 1000$ of income for a family in poverty results in children’s test score gains of about 0.06 standard deviations. Duncan, Morris, and Rodrigues (2011) find test score effects of a similar magnitude to those in Dahl and Lochner (2012) when they examine 11 random assignment experiments of welfare and anti-poverty programs from the 1990's. Michelmore (2013) shows that income changes from the EITC also lead to higher college enrollment and completion. Together, these studies suggest that changes in family finances and child health generated by Medicaid expansions could lead to impacts on long-run educational attainment.

\footnotetext{
${ }^{10}$ See Almond and Currie (2011) for a comprehensive overview of the fetal origins hypothesis and Eide and Showalter (2011) for evidence on the effect of health on human capital outcomes throughout the life cycle.
} 
While we provide the first analysis in the literature of the long-run effects of Medicaid on educational attainment, there are two papers in the literature that are closely associated with ours. The first paper is Levine and Schanzenbach (2009), which analyzes the effect of Medicaid and SCHIP expansions at birth on future educational achievement as measured by state-level NAEP scores. They examine differences in Medicaid expansion by state and the differences between age cohorts in a triple difference framework. Their results suggest that a 50 percentage point increase in Medicaid eligibility corresponds to a 0.09 standard deviation increase in reading test scores. They find no effect on math test scores, however.

Our analysis is distinguished from theirs along several dimensions. First, we focus on the effects of expanding health insurance to children of all ages. This question has been studied much less but is particularly important given the expected increase in the number of insured children due to the implementation of the ACA (Kenney et al., 2011) and the amount of money spent in the US on providing health care to children through Medicaid. ${ }^{11}$ Indeed, our results indicate that expanding eligibility to non-newborn children is an important driver of the long-run effects of Medicaid, which further highlights the relative contribution of our analysis. Second, we examine effects on long-run educational attainment rather than on test scores at younger ages. A growing body of evidence points to the effect of given educational interventions on test scores being a poor predictor of the effects on the longer-run outcomes that are of greater interest, such as educational attainment and earnings (e.g., Ludwig and Miller, 2007; Chetty et al., 2011; Deming et al., 2013). ${ }^{12}$

\footnotetext{
${ }^{11}$ If health insurance among school-age children did not positively affect these children, ostensibly the government could only offer Medicaid to pregnant women and households with very young children. Thus, it is important to understand what value there is to offering school-age children Medicaid.

${ }^{12}$ Much of this evidence suggests that it is particularly problematic to use effects on contemporaneous test scores to predict long-run outcomes. Levine and Schanzenbach (2009) examine effects on the NAEP scores of $4^{\text {th }}$ and $8^{\text {th }}$
} 
The second related work is a working paper by Brown, Kowalski and Lurie (2014). They use IRS tax data to examine the effect of Medicaid expansions throughout a child's early life on earnings. Because their data begin in 1996, they only observe their youngest cohorts at age 15, which means there could be potential problems associated with endogenous mobility. ${ }^{13}$ Nonetheless, they find results that are highly complementary to our own: Medicaid eligibility increases from 0-18 are associated with higher earnings, lower EITC receipt, and higher labor force participation. That they obtain these estimates on a different dataset using somewhat different cohorts is notable. Together, our results point to large effects of Medicaid expansions on the long-run outcomes of affected children.

\section{Data}

We use three sources of data in our analysis of the effects of insurance expansions on educational attainment. Below, we describe these sources of data, as well as the construction of the variables that we use in our investigation.

\subsection{Medicaid Eligibility Data}

Our Medicaid eligibility data are constructed for the years during which our 1980-1990 birth cohort are between the ages of 0-17 using the March Current Population Survey (CPS). We construct two eligibility measures, using state and year information on eligibility rules similar to those used in Gross and Notowidigdo (2011) and Gruber and Simon (2008). ${ }^{14}$ Eligibility

graders, which themselves are longer-run test score outcomes. Furthermore, instructors are unlikely to manipulate NAEP scores endogenously with respect to Medicaid eligibility rates, which would not necessarily be the case for contemporaneous test scores used to evaluate a given educational intervention. Nevertheless, it is not at all clear that effects on NAEP scores would translate into higher educational attainment, which underscores the importance of our analysis.

${ }^{13}$ Endogenous mobility is less of an issue in our analysis because we observe state of birth rather than one's state of residence at age 15 or older.

${ }^{14}$ We are extremely grateful to Tal Gross and Kosali Simon for providing us with the computer code that forms the basis for our eligibility calculations. 
calculations are based on the household's income, the age and number of children in the household, and the gender and unemployment status of the head of household.

The first Medicaid eligibility measure we construct is the proportion of households of a given race (white, nonwhite) with children of age $a$ in state $s$ and year $t$ who are eligible for Medicaid, where $a \in(0,1, \ldots 17)$. Thus, for example, we calculate the proportion of households with 5-year-olds in New York who are eligible for Medicaid in each year between 1980 and 2007. We calculate eligibility separately by child's race due to the strong correlation between race and Medicaid eligibility: a given change in eligibility rules is likely to impact nonwhites differently than whites even though the Medicaid rules themselves are race-neutral.

These calculations allow us to measure the proportion of children of each age and race group that are Medicaid-eligible in each state and in each year between 1980 and 2007. As described below, our outcome data span the years 2005-2012. We focus on the 1980-1990 birth cohorts who are between the ages of 22 and 29 in 2005-2012, which is why our CPS sample ends in 2007 (when the 1990 birth cohort is 17). ${ }^{15}$ Due to small sample sizes in the CPS, particularly within each age-race-state cell, we use three-year moving averages of calculated eligibility instead of yearly eligibility. ${ }^{16}$ Aside from making the estimates more precise, our use of these moving averages has little effect on the results. We refer to this measure of Medicaid eligibility as "actual eligibility."

Actual eligibility varies within states over time due to changes in eligibility rules, changes in demographic composition, and changes in the economic circumstances of households.

\footnotetext{
${ }^{15}$ We have conducted extensive sensitivity analyses using different birth cohort ranges and ACS age ranges. Our results are not very sensitive to the age range or birth cohorts used. These sensitivity analyses are available from the authors upon request.

${ }^{16}$ This method necessitates the use of CPS data through 2009 (which contains 2008 income information), to enable the construction of our 3-year moving average.
} 
In order to isolate the variation in Medicaid eligibility due to eligibility rule changes, we follow the method first used in Currie and Gruber (1996a, 1996b) and Cutler and Gruber (1996) and calculate the proportion of each state, age and race in each year that would be eligible for Medicaid using a fixed national sample that does not vary across states or over time. We use a 20\% national sample from the 1986 CPS and calculate the share of this fixed population with a child of age $a$ in year $t$ and race $r$ that would be eligible for Medicaid in each state using that state’s Medicaid eligibility rules in that year. The 20\% sample is comprised of 31,223 individuals, and these respondents are assigned to each state (including DC) so that the total sample size is 1.6 million $(31,223 \times 51)$. Critically, this sample does not vary by demographic characteristics across states or over time. Thus, this measure is unaffected by state- specific trends in populations or economic conditions that relate to both eligibility and coverage, (e.g. a state-level recession).

For each year, we use the same 1.6 million person sample and adjust family income for inflation using the Consumer Price Index for All Urban Consumers. We then calculate our measure of "simulated fixed eligibility" for individuals of a given state, age and race based on the federal- and state-specific Medicaid eligibility rules in effect in a given year. ${ }^{17}$ Finally, we collapse these estimates into unique state-year-age-race cells that yield the proportion of the fixed sample eligible for Medicaid in each cell. Since the fixed sample includes the same sample in every year, we calculate yearly eligibility rather than the three-year moving average that we use for actual eligibility.

Our baseline estimates include Medicaid eligibility variation coming from federal Medicaid expansions, state decisions about whether they will provide more generous benefits

\footnotetext{
${ }^{17}$ Of the initial 31,223 individuals in the fixed sample, 23,870 are white and 7,353 are nonwhite.
} 
than required by federal law, as well as the timing of state expansions and their generosity levels. Among these sources of variation, the one that is most worrisome is the timing of state expansions: state expansion decisions may be endogenous with respect to underlying trends in educational attainment. Thus, we also construct measures of Medicaid eligibility that only are a function of federal rules. Federal Medicaid rules have different impacts on states due to preexisting state-level AFDC policies. Hence, we fix AFDC rules in each state as of 1980 and then calculate 3-year moving average actual eligibility as well as yearly fixed simulated eligibility for each age, race and state that would occur only due to changes in federal regulations governing Medicaid eligibility thresholds. Put differently, our federal eligibility measures yield state-yearage-race eligibility that would occur if no states provided more generous Medicaid access than required under federal law. The reason this is not simply a cohort-based analysis, then, is that the effect of federal rules varies by state according to (fixed) welfare policies. By design, this source of Medicaid eligibility variation cannot be correlated with any decisions states can make regarding Medicaid policies.

Trends in our Medicaid eligibility measures, both overall and by race, are shown in Figure 1. For each birth cohort, we show the average eligibility between the ages of 0-17 to which the cohort was exposed. The panels of the figure show, for the 1980-1990 birth cohorts, actual eligibility that is a function of both state and federal rules as well as eligibility that uses only federal rules. As demonstrated in Figure 1, there was a dramatic rise in Medicaid eligibility that took place across the birth cohorts we study. Overall, average eligibility rates over the course of childhood increased 172\% between the 1980 and 1990 birth cohorts. Much of this was the non-linear increase in eligibility that came from the 1990 federal Medicaid expansion that extended eligibility to all children born after September 30, 1983 in families up to $100 \%$ of the 
poverty line. In the second and third panel of Figure 1, we show that the proportional increases experienced between whites and nonwhites were similar, but the higher baseline eligibility rates among nonwhites in 1980 led to much higher eligibility among the 1990 cohort than among the 1980 cohort. In our data, over 50\% of nonwhites born in 1990 were eligible for Medicaid over the course of their childhood, while less than $30 \%$ of whites were eligible among this birth cohort.

Figure 1 also shows that the trends in overall eligibility track the trends in federal eligibility closely, especially after the 1984 birth cohort, which highlights the importance of federal Medicaid policies for identification. The simulated eligibility trends are very close to the actual trends as well. Thus, most of the aggregate pattern in Medicaid eligibility is due to policy changes rather than demographic shifts in the US population.

\subsection{Educational Attainment}

The main outcome data we use come from the 2005-2012 American Community Survey (ACS). The ACS was designed to replace the Census, and thus the variables and design across the two surveys are almost identical. The sample for our analysis consists of birth cohorts from 1980-1990 who are between 22 and 29 in 2005-2012. Thus, for each individual in our sample, we observe eligibility in his or her birth state at each age between 0 and 17 . Table 1 shows the birth cohorts included in our analysis sample at each age and year. The top row shows the ACS (i.e., calendar) year, and the column shows the age of the respondent. For example, in the 2008 ACS, observations of 25 year olds come from the 1983 cohort. This table illustrates that we do not observe each birth cohort in each ACS survey due to our constructed age cutoffs. For example, 29 year olds are observed in 2009-2012 and come from the 1980-1983 birth cohorts only, whereas 25 year olds come from the 1980-1987 birth cohorts and are included in each of 
the ACS years in this analysis. Our use of 1980 as the earliest birth cohort is driven by our lack of information about state-specific Medicaid eligibility pre-1980, and thus it is not feasible to use earlier birth cohorts. ${ }^{18}$ Furthermore, we examine individuals only up to age 29 as by age 29 most education has been completed (Bound, Lovenheim and Turner, 2010). Including older individuals would reduce the number of calendar years in which we can identify eligibility for such respondents.

The central benefit of using the ACS data for this analysis is our ability to link each respondent to the state of his or her birth. Using the current state of residence is problematic because students may endogenously sort across states, especially if Medicaid indeed impacts education outcomes. One's state of birth is unlikely to be related to Medicaid rules, however, especially since prior work has found no link between Medicaid rules and fertility patterns (Zavodny and Bitler, 2010; DeLeire, Lopoo and Simon, 2011). We calculate, for each respondent, indicators for whether the person did not complete high school, whether she attended any college and whether she obtained a Bachelors Degree (BA). Our measure of high school completion includes GEDs, which is potentially problematic if Medicaid eligibility shifts students from obtaining a traditional high school diploma to a GED. ${ }^{19}$ In 2008 and after, however, the ACS asks directly about GED completion. Using data from 2008-2012, we find little evidence that our main high school completion results are being driven by GEDs, as shown in Table 4. We thus conclude that our use of pre-2008 data is not biasing the main conclusions

\footnotetext{
${ }^{18}$ We also note that Medicaid eligibility was very low pre-1980 and there were few expansions. Thus, our focus on birth cohorts between 1980 and 1990 captures most of the policy-driven variation in Medicaid exposure that has occurred since the program's inception.

${ }^{19}$ Heckman and LaFontaine (2006) present evidence that the returns to a GED are lower than the returns to a high school diploma. Thus, examining patterns of substitution across these degrees is of interest.
} 
one might draw from our results about the relationship between Medicaid and high school completion.

We collapse the data to birth cohort, state of birth, survey year, race (white/nonwhite) means for all variables, using the individual census weights. We then link each birth cohort, state-of-birth, race, survey year cell to the Medicaid eligibility means discussed in Section 4.1. In particular, we calculate average eligibility for each birth cohort in each survey year $(t)$, state of birth (s) and race $(r)$ over their childhood ages ( $a \in[0,17])$ :

$$
\text { eligibility }_{\text {sart }}=\frac{1}{18} \sum_{i=0}^{17} \overline{e l l g}_{\text {sirt }} \text {, }
$$

where $\overline{\operatorname{ellg}}_{\text {sirt }}$ is the average Medicaid eligibility in birth state $s$ and survey year $t$ of race $r$ when the individual was age $i$.

We construct an identical measure using fixed simulated eligibility:

$$
f s_{-} \text {eligibility }_{\text {sart }}=\frac{1}{18} \sum_{i=0}^{17}{\overline{f s_{-} e l i g}}_{\text {sirt }} \text {, }
$$

where fs_eligibility is fixed simulated Medicaid eligibility of those in a given birth cohort and race $(r)$ in state of birth (s) and survey year $(t)$ when the individual was age (a) that is calculated using a constant sample from the 1986 CPS, as described above.

Descriptive tabulations of the analysis data for the full sample and by race group are shown in Table 2. In the full sample, the average respondent is 25 , and about $68 \%$ of the respondents are white. The gender and age composition of the sample varies little across race groups. Furthermore, the educational attainment of nonwhites is much lower than whites, while average Medicaid eligibility is much higher for nonwhites. Both of these patterns reflect the strong correlation between socioeconomic status and race, which highlights the potential 
importance of any effect of Medicaid eligibility on educational attainment to help address gaps in educational outcomes between whites and nonwhites.

\section{Empirical Methodology}

To analyze the effect of Medicaid eligibility expansions on educational attainment, we use difference-in-difference methods, in which our identification strategy makes use of differences across states over time in both the eligibility criteria (which varies by income, age and family composition) and the timing of the expansions. Specifically, we estimate models of the following form:

$$
Y_{\text {sart }}=\beta_{0}+\beta_{1} \text { eligibility }_{\text {sart }}+\beta_{2} X_{\text {sart }}+\gamma_{r s}+\delta_{r t}+\theta_{r a}+\varepsilon_{\text {sart }}
$$

where $Y_{\text {sart }}$ is the educational outcome (high school non-completion rate, college attendance rate or college graduation rate) in state-of-birth $s$ for age $a$, of race $r$ in survey year $t$. The variable eligibility $_{\text {sart }}$ comes from equation (1) above and denotes the mean fraction of individuals between the ages of 0 and 17 who were eligible for Medicaid in state $s$ when respondents in year $t$ were aged $0-17$.

In the baseline specification, the vector $X_{\text {sart }}$ includes percent male and an indicator for whether the observation is for the nonwhite sample or not. As we discuss below, we then include in $X_{\text {sart }}$ some measures of potential confounding policies. The model includes as well a set of race-by-age fixed effects $\left(\theta_{r a}\right)$, race-by-state-of-birth fixed effects $\left(\gamma_{r s}\right)$ and race-by-calendar year fixed effects $\left(\delta_{r t}\right){ }^{20}$ The race-by-age fixed effects in particular are important because they account for the fact that older individuals have more time to complete their education and that this age pattern might be different across whites and nonwhites. The race-by-state fixed effects control for fixed differences across states that are correlated with both Medicaid eligibility and

\footnotetext{
${ }^{20}$ Henceforth, we will refer to "state fixed effects" and "state-of-birth fixed effects” synonymously.
} 
educational attainment, such as the higher education structure and the industrial mix in the state, which we allow to vary by race as well. The race-by-year fixed effects account for any economywide shocks that could be correlated with prior Medicaid expansions and that might be different across racial groups.

The coefficient of interest in equation (3) is $\beta_{1}$; conditional on the set of controls and fixed effects in the model, the variation used to identify this coefficient comes from increases in eligibility within state across birth cohorts over time. This is basically a difference-in-difference specification, where the treatment dose varies across different cohorts depending on the state and year of birth as well as on one's race. As discussed in Section 4, this variation comes from two sources: the first is rule changes that expand Medicaid eligibility to different populations within each state, and the second is demographic shifts that expand the proportion of individuals who meet pre-existing eligibility criteria.

For our analysis, the second source of variation is potentially problematic. If there are demographic changes that affect the proportion of people eligible for Medicaid, these changes are likely to be correlated with educational attainment. Our limited set of demographic controls cannot fully account for such changes, although demographic changes that expand Medicaid eligibility most likely generate a negative bias in estimating the effect of Medicaid on educational attainment. We therefore use an instrumental variables strategy that is robust to demographic shifts. This IV strategy amounts to using fs_eligibility from equation (2) as an instrument for eligibility. Because fs_eligibility is based on eligibility rules in each year using a fixed sample of individuals from the 1986 CPS, it is only affected by eligibility rule changes over time within states. 
Similar to any difference-in-difference analysis, there are two main assumptions we invoke. The first is that Medicaid expansions are not correlated with underlying trends in educational attainment across cohorts at the state level. A particular concern for our identification strategy would be if Medicaid expansions are occurring in states that are becoming more affluent. Then, even simulated fixed eligibility changes would be positively correlated with underlying and unobserved trends in educational attainment. We do not believe such a situation is likely, however, since states probably would be more compelled to expand Medicaid eligibility due to increased, not decreased demand for public insurance. This is a common identification assumption that has been invoked repeatedly in the Medicaid literature (e.g., Currie and Gruber, 1996a, 1996b; Cutler and Gruber, 1996; Gross and Notowidigdo, 2011; Gruber and Simon, 2008). The second assumption underlying our identification strategy is that there are no other state-level policies that are correlated with Medicaid expansions that themselves might affect educational attainment.

We provide an extensive set of robustness checks to provide additional confidence that our results are not being driven by endogenous state Medicaid eligibility expansions or by other policies. First, in some specifications we control for average state EITC amounts between the ages of 0-17 for each cohort. Prior work linking EITC policies to educational outcomes suggests EITC generosity could be a confounding factor if it is correlated with Medicaid generosity. ${ }^{21}$ We also control for average school spending per pupil in the years in which each cohort was 5-17, separately by urban, rural and suburban districts. Although there is a tenuous link between school expenditures and education outcomes (see Hanushek, 2003 for an overview of this literature), recent work has linked school spending increases from school finance reform to higher long-run

\footnotetext{
${ }^{21}$ See Michelmore (2013) for an overview of state-level EITC laws. We thank Kathy Michelmore for providing us with these data.
} 
educational outcomes (Jackson, Johnson and Persico, 2014). If such spending changes are correlated with Medicaid expansions, it could generate a bias in our results. We view these alternative policies as the two that are most likely to produce confounding effects, and our estimates that control for these policies provide evidence on whether this is so. In some specifications, we also include race-by-state-of-birth-by-year fixed effects as well as race-byage-by-year fixed effects. ${ }^{22}$ These fixed effects allow us to control flexibly for any contemporaneous age- or state-specific shocks, separately by race, which are correlated with prior Medicaid expansions.

We provide more direct evidence that endogenous state Medicaid expansions are not biasing our estimates by using only federal Medicaid eligibility rules as discussed in Section 4.1. The race-by-state-of-birth fixed effects control for the fixed differences in AFDC rules across states, and the identifying variation in the federal model comes solely through the fact that federal rule changes have differential impacts on states due to pre-existing AFDC policies. Thus, there is no scope in these models for endogenous state decisions regarding Medicaid, and to the extent we obtain similar results using this variation, it will provide confidence in the validity of the results that use state Medicaid variation as well. To the best of our knowledge, this is the first paper to provide estimates using only federal eligibility variation, so these results are of interest in their own right insofar as they help validate the widely-employed assumption that state Medicaid expansions are exogenous.

\footnotetext{
${ }^{22}$ Note that we do not control for race-by-state-by-age fixed effects. Thus, some of the identifying variation could be coming from fixed differences across ages within a state. However, this would require the existence of shocks to specific ages (but not birth cohorts) in a state that happen to be correlated with Medicaid eligibility differences. Furthermore, the estimates that use only federal variation would be unaffected by any such shocks. We have estimated models using these fixed effects, and the results are qualitatively similar (if somewhat less precise). We do not include them in the analysis because there is little economic justification for these controls.
} 
We also conduct robustness tests that include race and state of birth specific linear trends across birth cohorts. These models are identified off of the non-linear increases in Medicaid eligibility that followed from state and federal law changes, and they help guard against any upward bias from correlated secular trends in educational attainment and Medicaid eligibility. We further provide a robustness check in which we randomly assign observed eligibility levels across age-state-year cells. Overall, our estimates are robust to using variation in Medicaid eligibility from different sources and to the series of robustness checks we conduct. These findings support the validity of our identification strategy.

Because errors are unlikely to be independent within states of birth over time, we cluster all standard errors at the state-of-birth level. All estimates also are weighted using sample weights provided in the ACS.

\section{Results}

\subsection{Main Results}

Table 3 presents the main results from our estimation of equation (3). Each cell in the table comes from a separate regression, with Panel A showing results that use all Medicaid eligibility and Panel B showing results using only federal eligibility. The first column in the table presents the first stage, which shows how a change in fixed simulated eligibility translates into actual eligibility. The table also shows the effect of actual Medicaid eligibility (“OLS”) and fixed simulated eligibility (“RF,” for reduced form) on high school non-completion, college enrollment and four-year college completion as well as the associated IV estimates.

Across outcomes and the specifications shown in different rows, we find consistent evidence that Medicaid eligibility when young increases educational attainment. Focusing on the baseline IV results in row (1), a 10 percentage point increase in fixed simulated eligibility 
reduces high school non-completion by 0.38 of a percentage point, increases college enrollment by 0.30 of a percentage point, and increases BA attainment by 0.61 of a percentage point. The high school and college completion estimates are statistically significantly different from zero at the $5 \%$ level and $10 \%$ levels, respectively. Relative to the mean attainment rates shown in Table 2, these estimates translate into a $4.0 \%$ decline in high school dropouts and a $2.3 \%$ increase in BA receipt. As shown in Figure 1, there was a 24 percentage point increase in average eligibility during childhood between the 1980 and 1990 birth cohorts. Our estimates suggest this change would have reduced high school non-completion by $9.7 \%$ and increased college completion by $5.5 \%{ }^{23}$

To put these effects in perspective, it is helpful to compare them to educational attainment trends over this period. Murnane (2013) shows that high school graduation rates increased by about 6 percentage points between the 1980 and 1990 birth cohorts. Since a 24 percentage point increase in Medicaid would increase high school completion by 0.9 percentage points, our results indicate that $15 \%$ of this increase can be attributed to Medicaid expansions. Our tabulations from the Current Population Survey indicate that college completion rates among 23-year olds between the 1980 and 1990 birth cohorts increased by 4.8 percentage points. A 24 percentage point Medicaid eligibility increase would increase BA attainment by 1.5 percentage

\footnotetext{
${ }^{23}$ It is likely that these gains in educational attainment are even more pronounced among those that take up Medicaid. We estimate take-up of Medicaid in our cohorts as well and find results similar to those in Gruber and Simon (2008). These estimates are available from the authors upon request. However, we note that neither these estimates nor those in the literature elsewhere (Cutler and Gruber 1996) are the appropriate "first stages" in our context. These estimates provide the contemporaneous effects on take-up, where we would need an estimate of the effect on take-up over one's entire childhood to match our reduced form results. Unfortunately, no comprehensive longitudinal datasets exist with sufficient sample size to allow us to estimate this relationship. The CPS, which we use for the contemporaneous take-up results, is not sufficient, for while it has many waves of data, it does not follow the same families over many years. Following the majority of the Medicaid literature, we therefore focus on eligibility rather than on take-up.
} 
points using the baseline results, which implies that Medicaid expansions can explain 30.5\% of the overall BA attainment increases over this period.

How do these effect sizes compare to effects from other education interventions? Such comparisons are complicated by the fact that we are examining attainment at relatively older ages, which is rare in the literature examining early lifetime interventions. One point of comparison is the class size literature. Dynarski, Hyman and Schanzenbach (2013) show the effects of the Tennessee STAR class size experiment on BA attainment. Their estimates point to a 1.6 percentage point increase in the likelihood of BA receipt due to being randomized into a smaller class in primary school. Deming et al. (2014) show lottery-based results from an open enrollment system in the Charlotte-Mecklenburg schools that winning a lottery and thus attending a higher-quality high school increases the likelihood of college completion by 4.7 percentage points. In their analysis of school accountability, Deming et al. (2013) estimates that a 1 percentage point increase in the likelihood of being subject to accountability sanctions for low-performing students increases their high school graduation rate by 1 percentage point and increases their BA attainment rate by 0.6 of a percentage point. Finally, Garces, Thomas and Currie (2002) show that Head Start participants are 4 percentage points more likely to graduate from high school in estimates that control for selection using mother fixed effects. Overall, our estimates indicate that a 10 percentage point Medicaid expansion produces educational attainment increases that are either of equal size or somewhat smaller than these other notable educational interventions.

Rows (2)-(4) of Table 3 show our estimates are largely robust to adding additional controls for EITC and school spending (row 2) as well as race-state-year and race-age-year fixed effects (rows 3 and 4) into the models. The high school non-completion estimates become 
slightly smaller in absolute value, but they also become less precise. Qualitatively, they do not change by much. The other estimates change little in terms of magnitude, but all are less precisely estimated due to the demanding nature of these models.

Table 3 also demonstrates that the OLS and reduced form/IV results are quite different from each other. The OLS estimates in Panel A show Medicaid eligibility increases are associated with smaller high school dropout declines and with smaller college completion increases. These results are suggestive that the bias from failing to account for the correlation between demographics and Medicaid eligibility would cause one to find a smaller effect of Medicaid on educational attainment. Once this confounding factor is controlled for, however, Table 3 indicates Medicaid expansions have a positive and sizable impact on long-run educational attainment.

Panel B of Table 3 shows estimates that use only federal Medicaid eligibility. Focusing on the baseline estimates in row (5), we show that federal eligibility expansions reduce high school dropout and increase college enrollment and completion. Comparing the estimates in row (5) to the baseline results in row (1), the point estimates for the reduced form are smaller in absolute value when only the federal variation is used. As the IV estimates show, this difference mostly reflects the smaller first stage. In Panel A, the first-stage estimates are around 0.9, suggesting that a 10 percentage point change in fixed simulated eligibility is associated with a 9 percentage point change in actual eligibility. ${ }^{24}$ As expected, the link between federal Medicaid rules and actual eligibility is much weaker because we are ignoring state responses to the federal

\footnotetext{
${ }^{24}$ Our first-stage estimates are similar to what has been found in prior work. Cutler and Gruber (1996) report a firststage of 0.84 for children and 0.95 for women, while Gross and Notowidigdo (2011) have an implied first-stage estimate of 0.61 .
} 
regulation changes. However, the first stage for the federal variation still is sizable in magnitude and is statistically significant from zero at the $1 \%$ level.

Comparing the IV estimates from similar models across panels shows that using the federal variation only produces results that are quantitatively and qualitatively similar to the estimates that use state variation as well. For high school non-completion in the baseline specification (row 1), the estimates indicate a 10 percentage point eligibility increase during childhood reduces dropout by 0.38 of a percentage point using all Medicaid variation, and it reduces dropout by 0.55 of a percentage point using only federal variation (row 5). For college enrollment, the estimates in row (5) are smaller than those in row (1), and they are inconsistent with all but a small increase in college attendance. Finally, for college completion, the IV coefficients across panels of Table 3 show very similar effects of Medicaid eligibility expansions. Comparisons of rows (2) and (6) show that our estimates using federal variation are robust to the inclusion of EITC and school spending controls as well. ${ }^{25}$ That these two models yield similar estimates of the effect of changes in Medicaid eligibility among children on longrun educational attainment supports our use of all Medicaid variation, as it suggests state Medicaid eligibility variation is not endogenous with respect to long-run educational outcomes.

A final potential concern with the results in Table 3 is that the high school completion variable groups GED and high school diploma recipients together. Starting in 2008, the ACS began asking separately about high school diploma and GED receipt, and in Table 4 we present estimates using 2008-2012 data where we separate high school diploma non-receipt from diploma and GED non-receipt. Henceforth, we will only present IV and OLS estimates due to

\footnotetext{
${ }^{25}$ We do not present federal variation results that include race-state-year and race-age-year fixed effects. Due to the limited amount of variation in federal Medicaid eligibility, including these fixed effects yields large standard errors that make the resulting estimates uninformative.
} 
space considerations; reduced form estimates are available upon request. As the table demonstrates, the effects are extremely similar across the two measures of high school completion, suggesting that our baseline estimates do not obscure potential shifts between traditional diplomas and GEDs. In addition, the some college and college plus estimates are similar in the 2008-2012 sample, if somewhat larger among all outcomes. These results suggest our estimates are not driven by the particular sample period we chose.

\subsection{Educational Attainment Results by Race and Age at Expansion}

Thus far, we have estimated models that pool effects across racial groups. But, given persistent racial disparities in educational attainment, heterogeneous effects by race are of considerable interest. In Online Appendix Tables A-1 and A-2, we estimate our models separately for whites and nonwhites, respectively. For whites, the effects on high school noncompletion are negative, but they are smaller in absolute value than in the pooled model and they are not statistically significant at conventional levels. Particularly when we include the full set of fixed effects and when we use only federal variation, there is a positive effect of Medicaid on college enrollment for whites. The effect is on the order of 1.0 to 1.3 percentage points for each 10 percentage point increase in Medicaid eligibility. There also is a sizable, positive effect on college completion for whites, especially using the federal variation. While these point estimates are large - suggesting a 2.5 percentage point increase from a 10 percentage point Medicaid eligibility increase - they are consistent with observed increases in white college completion across these cohorts. ${ }^{26}$

\footnotetext{
${ }^{26}$ CPS tabulations indicate that college completion rates among white 23 year olds increased by 6.4 percentage points between the 1980 and 1990 birth cohorts. White Medicaid eligibility expanded by 19 percentage points across cohorts, which would increase BA attainment rates by $4.75(=0.25 * 0.19 * 100)$ percentage points. This is $74 \%$ of the total BA attainment increase over this period.
} 
Among nonwhites, the effects on high school non-completion are particularly large. We find that high school non-completion is reduced by about $0.45-0.59$ percentage points for each 10 percentage point increase in Medicaid eligibility. There is little evidence of a college enrollment effect, and although we find an increase in college completion, it is smaller than for the white sample. Taken together, these estimates are consistent with a larger effect of Medicaid eligibility for whites on higher education attendance and completion and a larger effect for nonwhites on high school completion.

As discussed in Section 3.2., one of the contributions of this paper is to identify whether there are effects of health insurance access after birth. Since prior work in this area has examined effects of Medicaid eligibility among pregnant women, our estimates are informative about any impacts of public health insurance among older children. In Table 5, we present IV estimates of equation (3) that control separately for Medicaid eligibility when a respondent was 0-3, 4-8, 9-13 and 14-17. In Panel A, we show results from the baseline specification, while in Panel B we include our full set of fixed effects (akin to row 4 in Table 3).

The results are not precise, due to the demanding nature of this specification, and there are no strong age patterns that emerge. What is striking about these results is that they suggest that Medicaid expansions at all ages are important for long-run outcomes such as education. Thus, our results indicate that expanding Medicaid eligibility to children after birth (and infancy) can have a substantial effect on long-run educational attainment. This finding sheds some light on why our estimates are somewhat larger than those in Levine and Schanzenbach (2009), who examine test score effects of Medicaid eligibility at birth. Our results show that educational outcomes, at least in the longer-run, are sensitive to Medicaid expansions that target school-age children as well. 


\subsection{Robustness Checks}

In this section, we present two robustness checks that yield additional insight into the validity of our central identifying assumption, namely that there are not differential underlying trends in educational attainment correlated with public health insurance eligibility expansions. First, in Table 6, we present results from the models presented in Table 3 that also include statespecific linear birth cohort trends, separately by race. If there are differential trends in educational attainment correlated with Medicaid expansions, these results should yield substantively different results from our baseline model. However, the results are very similar to those in Table 3, suggesting that linear differences in trends across states are not biasing our baseline estimates.

Second, in Table 7, we show the mean and the $2.5^{\text {th }}$ and $97.5^{\text {th }}$ percentiles from 500 simulations that randomly assign Medicaid eligibility and fixed simulated eligibility across agestate-year cells. That is, we take combinations of actual and fixed simulated eligibility, and as a pair randomly assign them to different age-state-year cells, separately by race. This assignment is done with replacement. Both for the baseline model and for the model including race-stateyear and race-age-year fixed effects, the average estimates are very close to zero. Furthermore, the non-parametric confidence intervals suggests these null estimates are precisely estimated. This robustness check suggests the results presented in Table 3 are due to the specific way the Medicaid eligibility expansions were rolled out over time within states. When we randomly assign eligibility levels, they are no longer meaningfully related to educational attainment.

\subsection{The Effect of Childhood Medicaid Eligibility on Teen Health}

As discussed in Section 4, one of the main mechanisms through which public health insurance can affect long-run educational attainment is through promoting better health amongst 
children. In order to examine the potential importance of this mechanism, we estimate the effect of Medicaid eligibility during childhood on health outcomes in the teenage years. To do this analysis, we use the Youth Risk Behavior Surveillance System (YRBSS), which is a nationallyrepresentative survey of $9^{\text {th }}$ to $12^{\text {th }}$ grade students that is conducted by the Centers for Disease Control (CDC). ${ }^{27}$ The data are available from $1991-2011^{28}$ and contain state identifiers, so we can estimate equation (3) using these data with health outcomes as the dependent variable. A central drawback of these data, however, is that we do not observe state of birth, only state of current residence. These estimates therefore are potentially biased by endogenous mobility.

Table 8 contains health outcome estimates from the YRBSS data. Here, we calculate Medicaid eligibility from age 0 up until each respondent’s age. Thus, for a 15-year-old, the eligibility measure is average eligibility in the respondent's state of residence he/she would have experienced between the ages of $0-14$. These estimates also include race-state-year and race-ageyear fixed effects. Across virtually all measures of health outcomes, Table 8 shows that Medicaid eligibility during childhood translates into better health and better health behaviors by the time one is a teenager. However, due to low power, the standard errors are large, rendering these estimates more suggestive than conclusive. Still, they are informative as to a key mechanism likely driving our results.

The first row of Table 8 includes as a dependent variable a risky sex index that we construct based on several questions regarding sexual activity, ${ }^{29}$ and our IV results indicate a 10 percentage point increase in Medicaid eligibility during youth reduces risky sexual behavior by

\footnotetext{
${ }^{27}$ These data can be accessed at: http://www.cdc.gov/HealthyYouth/yrbs/index.htm?s_cid=tw_cdc16.

${ }^{28}$ We limit our sample to years 1995-2007 because in these years sample respondents between the ages of 14 and 18 are most similar to the 1980 to 1990 birth cohorts we analyze using ACS data.

${ }^{29}$ See Online Appendix Table A-3 for a list of the variables used to construct this index as well as individual estimates for each measure. The variables that constitute this index are indented directly below the Risky Sex Index in the table. We also report the individual estimates for the variables that make up our measures of whether a respondent has a mental health issue or an eating disorder in Online Appendix Table A-3.
} 
3.5\% relative to the sample mean. ${ }^{30}$ There is, however, an increase in the likelihood of being sexually active due to public health insurance eligibility. Thus, while teens are having sex more, they are practicing safer sex on average.

Our results suggest that those exposed to higher Medicaid eligibility at young ages have lower weight as well. There is a negative effect of Medicaid eligibility on BMI, on the order of a $3.9 \%$ reduction relative to the sample mean from a 10 percentage point increase in eligibility. We also find, as indicated in rows 4 and 5, that the likelihood of being overweight or obese declines considerably. In addition, there are sizable, though imprecisely estimated, declines in the likelihood of smoking marijuana, smoking cigarettes, and in alcohol consumption due to Medicaid eligibility. Medicaid expansions are associated with mentally healthier teens as well, as measured with a mental health index as well as by the prevalence of eating disorders.

That teens with higher Medicaid eligibility throughout their childhoods are healthier and have fewer harmful health behaviors suggests that they are indeed utilizing the medical services that are provided to them, are healthier as a result, and that increased health is one mechanism that is driving the educational attainment effects we find. To the extent that such increases in health enter into the education production function, they are likely to be one of the mechanisms driving the higher educational attainment that stems from the same Medicaid eligibility increases. While more work is necessary to clearly understand the role of health in producing educational outcomes, these results provide suggestive evidence that such a link is present and that health may be an important input into the education production function.

\section{Conclusion}

\footnotetext{
${ }^{30}$ The first stage estimate for these regressions is 0.882 , with a standard error of 0.123 .
} 
In this paper, we provide the first evidence on the effects of public health insurance expansions on long-run educational attainment in the US. Overall, our results suggest large effects of childhood Medicaid expansions on eventual educational outcomes. Our baseline estimates indicate that a 10 percentage point increase in Medicaid eligibility between the ages of 0 and 17 decreases the likelihood of not completing high school by approximately $4.0-5.9 \%$ and increases the 4-year college completion rate by $2.3 \%-3.0 \%$. The effects on high school completion are largest among nonwhites, while the effects on college attendance and completion are largest for whites. We also present evidence that public health insurance expansions when children are of school age are closely linked with long-run educational attainment; eligibility expansions beyond birth lead to higher educational attainment. To the best of our knowledge, these are the first estimates to demonstrate the importance of health insurance eligibility amongst older children, particularly as it relates to educational outcomes. Our analysis concludes by showing that the health insurance expansions we examine also translate into better health amongst teenagers, which we posit is an important mechanism through which health insurance access for children impacts their educational attainment.

Although the public health insurance expansions we study occurred in the past several decades, our results have several implications that are important for current public policy. First, they suggest that the long-run benefits of providing health insurance to low-income children may be much larger than the short-run gains. Evidence pointing to the large and growing returns to educational attainment (e.g., Autor, Katz and Kearney, 2008) as well as the importance of education in increasing intergenerational economic mobility (Black and Devereaux, 2011; Chetty et al., 2014) suggests that the returns on the public investments in health insurance in the 1980s and 1990s will be realized for some time. 
Second, our results relate to current policy discussions over the future of the SCHIP program, which have accompanied the larger debate over the ACA. More specifically, the ACA prohibits states from imposing eligibility and enrollment standards for Medicaid and SCHIP that were more restrictive than those in place in March 2010 (when the ACA was passed) until 2019. However, there have been attempts in Congress to repeal these provisions, which would essentially allow states to cut SCHIP benefits and eligibility. In addition, SCHIP funding is up for re-authorization in 2015, and its passage is far from assured. A back-of-the-envelope calculation indicates that eliminating the SCHIP program would reduce eligibility for public health insurance by 15.4 percentage points. Our baseline estimates suggest such a decline would increase the high school dropout rate by six-tenths of a percentage point and would decrease the college enrollment rate by five-tenths of a percentage point and the college completion rate by 0.9 of a percentage point. The results from this study highlight the need to account for the types of long-run effects of public health insurance provision when considering changes to the publicly provided health care system that is targeted at low-income children. 


\section{References}

Adams, Peter, Michael D. Hurd, Daniel McFadden, Angela Merrill, and Tiago Ribiera. 2003.

"Healthy, Wealthy, and Wise? Tests for Direct Causal Paths between Health and

Socioeconomic Status.” Journal of Econometrics 112(1): 3-56.

Alcaraz, Carlo, Daniel Chiquiar, Maria Jose Orraca, and Alejandrina Salcedo. 2013. “The Effect of Publicly Provided Health Insurance on Education Outcomes in Mexico.” Working Paper. Available at: http://vox.lacea.org/pdf/lacea2013_the_effect_publicly.pdf [Accessed October 2, 2014].

Almeida, R., L.C. Dubay, and G. Ko. 2001. "Access to Care and Use of Health Services by LowIncome Women.” Health Care Financing Review 22(4):27-47.

Almond, Douglas. 2006. "Is the 1918 Influenza Pandemic Over? Long-Term Effects of In Utero Influenza Exposure in the Post-1940 U.S. Population.” Journal of Political Economy 114(4): 672-712.

Almond, Douglas, and Janet Currie. 2011. "Killing Me Softly: The Fetal Origins Hypothesis.” The Journal of Economic Perspectives 25(3): 153-172.

Almond, Douglas, Lena Edlund, and Marten Palme. 2009. "Chernobyl's Subclinical Legacy: Prenatal Exposure to Radioactive Fallout and School Outcomes in Sweden.” Quarterly Journal of Economics 124: 1729-1772.

Almond, Douglas and Bhashkar Mazumder. 2011. "Health Capital and the Prenatal Environment: The Effect of Ramadan Observance During Pregnancy." American Economic Journal: Applied Economics 3: 56-85.

Autor, David H., Lawrence F. Katz, and Melissa S. Kearney. 2008. "Trends in U.S. Wage Inequality: Revising the Revisionists.” Review of Economics and Statistics 90 (2): 300-323.

Bailey, Martha and Susan Dynarski. 2011. "Gains and Gaps: Changing Inequality in US College Entry and Completion.” NBER Working Paper No. 17633.

Baldwin, Laura-Mae, Eric H. Larson, Frederick A. Connell, Daniel Nordlund, Kevin C. Cain, Mary Lawrence Cawthon, Patricia Byrns, and Roger A. Rosenblatt. 1998. "The Effect of Expanding Medicaid Prenatal Services on Birth Outcomes.” American Journal of Public Health 88(11): 1623-1629.

Banthin, Jessica S., and Thomas M. Selden. 2003. "The ABCs of Children's Health Care: How the Medicaid Expansions Affected Access, Burdens, and Coverage Between 1987 and 1996." Inquiry 40(2): 133-145.

Black, Sandra E. and Paul J. Devereux. 2011. "Recent Developments in Intergenerational Mobility.” In Card, D., Ashenfelter, O. (Eds.), Handbook of Labor Economics, vol. 4, Part B. Elsevier: Amsterdam.

Black, Sandra E., Paul J. Devereux, and Kjell G. Salvanes. 2007. "From the Cradle to the Labor Market? The Effect of Birth Weight on Adult Outcomes." Quarterly Journal of Economics,122(1): 409-439.

Bleakley, Hoyt. 2007. "Disease and Development: Evidence from Hookworm Eradication in the American South.” The Quarterly Journal of Economics 122 (1): 73-117.

Bleakley, Hoyt. 2010. "Malaria Eradication in the Americas: A retrospective Analysis of Childhood Exposure.” American Economic Journal: Applied Economics 2(2): 1-45.

Bound, John, Michael F. Lovenheim and Sarah Turner. 2010. "Why Have College Completion Rates Declined? An Analysis of Changing Student Preparation and Collegiate Resources.” American Economic Journal: Applied Economics 2(3): 129-157. 
Brown, David, Amanda E. Kowalski, and Ithai Lurie. 2014. "Medicaid as an Investment in Children: What is the Long-Term Impact on Tax Receipts?” Yale University Working Paper, available at http://www.econ.yale.edu/ ak669/medicaid.latest.draft.pdf, last accessed 10/7/2014.

Buchmueller, Thomas C., Kevin Grumbach, Richard Kronick, and James G. Kahn. 2005. "Book Review: The Effect of Health Insurance on Medical Care Utilization and Implications for Insurance Expansion: A Review of the Literature.” Medical Care Research and Review 62(1): 3-30.

Case, Anne, Angela Fertig, and Christina Paxson. 2005. "The Lasting Impact of Childhood Health and Circumstance.” Journal of Health Economics 24(2): 365-389.

Case, Anne, Darren Lubotsky, and Christina Paxson. 2002. "T Economic Status and Health in Childhood: The Origins of the Gradient.” American Economic Review 92(5): 1308-1334.

Carneiro, Pedro and James J. Heckman. 2002. "The Evidence on Credit Constraints in PostSecondary Schooling.” The Economic Journal 112(482): 705-734.

Chen, Yuyu, and Ginger Zhe Jin. 2012. "Does Health Insurance Coverage Lead to Better Health and Educational Outcomes? Evidence from Rural China.” Journal of Health Economics 31(1): 1-14.

Chetty, Raj, John N. Friedman, Nathaniel Hilger, Emmanuel Saez, Diane Whitmore Schanzenbach, and Danny Yagan. 2011. "How Does Your Kindergarten Classroom Affect Your Earnings? Evidence from Project Star.” Quarterly Journal of Economics 126(4): 15931660.

Chetty, Raj, John N. Friedman, and Jonah Rockoff. 2013. Measuring the Impacts of Teachers II: Teacher Value-Added and Student Outcomes in Adulthood.” NBER Working Paper No. 19424.

Chetty, Raj, Nathaniel Hendren, Patrick Kline and Emmanuel Saez. 2014. "Where is the Land of Opportunity? The Geography of Intergenerational Mobility in the United States.” NBER Working Paper No. 19843.

Clark, Damon and Heather Royer. 2013. "The Effect of Education on Adult Mortality and

Health: Evidence from Britain.” American Economic Review 103(6): 2087-2120.

Currie, Janet. 2000. "Do Children of Immigrants Make Differential Use of Public Health Insurance?” In Issues in the Economics of Immigration, pp. 271-308. University of Chicago Press.

Currie, J., M. Stabile, P. Manivong, and L. L. Roos. 2010. “Child Health and Young Adult Outcomes.” Journal of Human Resources 45(3): 517-548.

Currie, Janet, and Douglas Almond. 2011. "Human Capital Development Before Age Five.” Handbook of Labor Economics 4: 1315-1486.

Currie, Janet, and Jonathan Gruber. 1996a. "Health Insurance Eligibility, Utilization of Medical Care, and Child Health." The Quarterly Journal of Economics 111(2): 431-466.

Currie, Janet, and Jonathan Gruber. 1996b. "Saving Babies: The Efficacy and Cost of Recent Changes in the Medicaid Eligibility of Pregnant Women.” Journal of Political Economy CIV: 1263-1296.

Cutler, David M., and Jonathan Gruber. 1996. "Does Public Insurance Crowd Out Private Insurance?” The Quarterly Journal of Economics 111(2): 391-430.

Cutler, David M. and Adriana Lleras-Muney. 2006. "Education and Health: Evaluating Theories and Evidence.” NBER Working Paper No. 12352. 
Cox, Tamara Lalovic and Randall Reback. 2013. "Where Health Policy Meets Education Policy: School-based Health Centers in New York.” Mimeo.

Dafny, Leemore and Jonathan Gruber. 2005. "Public Insurance and Child Hospitalizations: Access and Efficiency Effects.” Journal of Public Economics 89(1): 109-129.

Dahl, Gordon B. and Lance Lochner. 2012. "The Impact of Family Income on Child Achievement: Evidence from the Earned Income Tax Credit.” American Economic Review 102(5): 1927-1956.

Dave, Dhaval M., Sandra L. Decker, Robert Kaestner, and Kosali Ilayperuma Simon. 2013. “The Effect of Medicaid Expansions in the Late 1980s and Early 1990s on the Labor Supply of Pregnant Women.” NBER Working Paper No. w19161.

DeLeire, Thomas, Leonard M. Lopoo, and Kosali I. Simon. 2011. "Medicaid Expansions and Fertility in the United States.” Demography 48(2): 725-747.

DeNavas-Walt, C., Bernadette D. Proctor, and Jessica C. Smith. 2013. “Income, Poverty, and Health Insurance Coverage in the United States: 2012.” Washington, DC: US Department of Commerce Economics and Statistics Administration, US Census Bureau. Retrieved October 2, 2014.

Deming, David, Sarah Cohodes, Jennifer Jennings, and Sandy Jencks. 2013. "School Accountability, Postsecondary Attainment and Earnings.” NBER Working Paper No. 19444.

Deming, David, Justine Hastings, Thomas Kane, and Douglas Staiger. 2014. "School Choice, School Quality and Postsecondary Attainment.” American Economic Review 104(3): 9911013.

Duncan, Greg. J., Pamela A. Morris, and Chris Rodrigues. 2011. “Does Money Really Matter? Estimating Impacts of Family Income on Young Children's Achievement with Data from Random-assignment Experiments.” Developmental Psychology 47(5): 1263-1279.

Dynarski, Susan, Joshua Hyman, and Diane Whitmore Schanzenbach. 2013. "Experimental Evidence on the Effect of Childhood Investments on Postsecondary Attainment and Degree Completion.” Journal of Policy Analysis and Management 32(4): 692-717.

Eide, Eric R., and Mark H. Showalter. 2011. "Estimating the Relation between Health and Education: What Do We Know and What Do We Need to Know?” Economics of Education Review 30(5): 778-791.

Figlio, David N., Jonathan Guryan, Krzysztof Karbownik, and Jeffrey Roth. 2013. "The Effects of Poor Neonatal Health on Children's Cognitive Development.” NBER Working Paper No. 18846.

Finkelstein, Amy, Sarah Taubman, Bill Wright, Mira Bernstein, Jonathan Gruber, Joseph P. Newhouse, Heidi Allen, and Katherine Baicker. "The Oregon Health Insurance Experiment: Evidence from the First Year.” The Quarterly Journal of Economics 127(3): 1057-1106.

Garces, Eliana, Duncan Thomas and Janet Currie. 2002. "Longer-Term Effects of Head Start.” American Economic Review 92(4): 999-1012.

Gross, Tal, and Matthew J. Notowidigdo. 2011. "Health Insurance and the Consumer Bankruptcy Decision: Evidence from Expansions of Medicaid.” Journal of Public Economics 95(7): 767-778.

Grossman, Michael. 1972. "On the Concept of Health Capital and the Demand for Health.” Journal of Political Economy 80(2): 223-255.

Grossman, Michael. 2004. "The Demand for Health, 30 Years Later: A Very Personal Retrospective and Prospective Reflection.” Journal of Health Economics 23(4): 629-636. 
Gruber, Jonathan. 2003. “Medicaid.” In Robert Moffitt (Ed.), Means Tested Transfer Programs in the U.S. Chicago: University of Chicago Press, pp. 15-77.

Gruber, Jonathan, and Kosali Simon. 2008. "Crowd-out 10 Years Later: Have Recent Public Insurance Expansions Crowded Out Private Health Insurance?” Journal of Health Economics 27(2): 201-217.

Hanushek, Eric A. 2003. “The Failure of Input-Based Schooling Policies.” The Economic Journal 113(485): F64-F98.

Heckman, James J. and Paul A. LaFontaine. 2006. “Bias-Corrected Estimates of GED Returns.” Journal of Labor Economics 24(3): 661-700.

The Henry J. Kaiser Family Foundation. Federal and State Share of Medicaid Spending, FY2012. Available Online: http://kff.org/medicaid/state-indicator/federalstate-share-ofspending/. Accessed May 13, 2014.

Jackson, C. Kirabo, Rucker Johnson, and Claudia Persico. 2014. "The Effect of School Finance Reforms on the Distribution of Spending, Academic Achievement, and Adult Outcomes.” NBER Working Paper No. 20118.

Kaestner, R.,T. Joyce, and A. Racine. 2001. "Medicaid Eligibility and the Incidence of Ambulatory Care Sensitive Hospitalizations for Children.” Social Science Medicine 52(2): 305-13.

Kaestner, R., A. Racine, and T. Joyce. 2000. "Did Recent Expansions in Medicaid Narrow Socioeconomic Differences in Hospitalization Rates of Infants?” Medical Care 38(2): 195206.

Kenney, Genevieve M., Matthew Buettgens, Jocelyn Guyer, and Martha Heberlein. "Improving coverage for children under health reform will require maintaining current eligibility standards for Medicaid and CHIP." Health Affairs 30, no. 12 (2011): 2371-2381.

Levy, Helen, and David Meltzer. 2008. “The Impact of Health Insurance on Health.” Annual Review of Public Health 29: 399-409.

Levine, Philip B. and Diane Schanzenbach. 2009. "The Impact of Children's Public Health Insurance Expansions on Educational Outcomes.” Forum for Health Economics \& Policy 12(1): 1-26.

Lo Sasso, Anthony T. and Thomas C. Buchmueller. 2004. "The Effect of the State Children's Health Insurance Program on Health Insurance Coverage.” Journal of Health Economics 23(5): 1059-1082.

Lovenheim, Michael F., Randall Reback and Leigh Wedenoja. 2013. "How Does Access to Health Care Affect Health and Education? Evidence from School-based Health Center Openings.” Mimeo.

Ludwig, Jens and Douglas Miller. 2007. “Does Head Start Improve Children's Life Chances? Evidence from a Regression Discontinuity Design.” Quarterly Journal of Economics 122(1): 159-208.

Michelmore, Katherine. 2013. "The Effect of Income on Educational Attainment: Evidence from State Earned Income Tax Credit Expansions.” Mimeo.

Miller, Sarah Marie, and Laura R. Wherry. 2014. "The Long-Term Health Effects of Early Life Medicaid Coverage.” Available at SSRN 2466691.

Moss, Nancy E. and Karen Carver. 1998. “The Effect of WIC and Medicaid on Infant Mortality in the United States.” American Journal of Public Health 88(9): 1354-1361.

Murnane, Richard. 2013, January. "U.S high school graduation rates: Patterns and explanations.” Working Paper 18701, National Bureau of Economic Research. 
Oreopoulos, Philip, Mark Stabile, Randy Walld, and Leslie L. Roos. 2008. "Short-, Medium-, and Long-Term Consequences of Poor Infant Health: An Analysis Using Siblings and Twins.” Journal of Human Resources 43(1): 88-138.

Phelps, C. 1997. Health Economics, 2nd ed. Reading, MA: Addison-Wesley.

Royer, Heather. 2009. "Separated at Girth: US Twin Estimates of the Effects of Birth Weight." American Economic Journal: Applied Economics 1(1): 49-85.

Todd, Petra E. and Kenneth I. Wolpin. 2007. "The Production of Cognitive Achievement in Children: Home, School, and Racial Test Score Gaps.” Journal of Human Capital 1(1): 91136.

Zavodny, Madeline and Marianne P. Bitler. 2010. “The Effect of Medicaid Eligibility Expansions on Fertility.” Social Science \& Medicine 71(5): 918-924. 


\section{Figure 1: Medicaid Eligibility by Birth Cohort and Race}
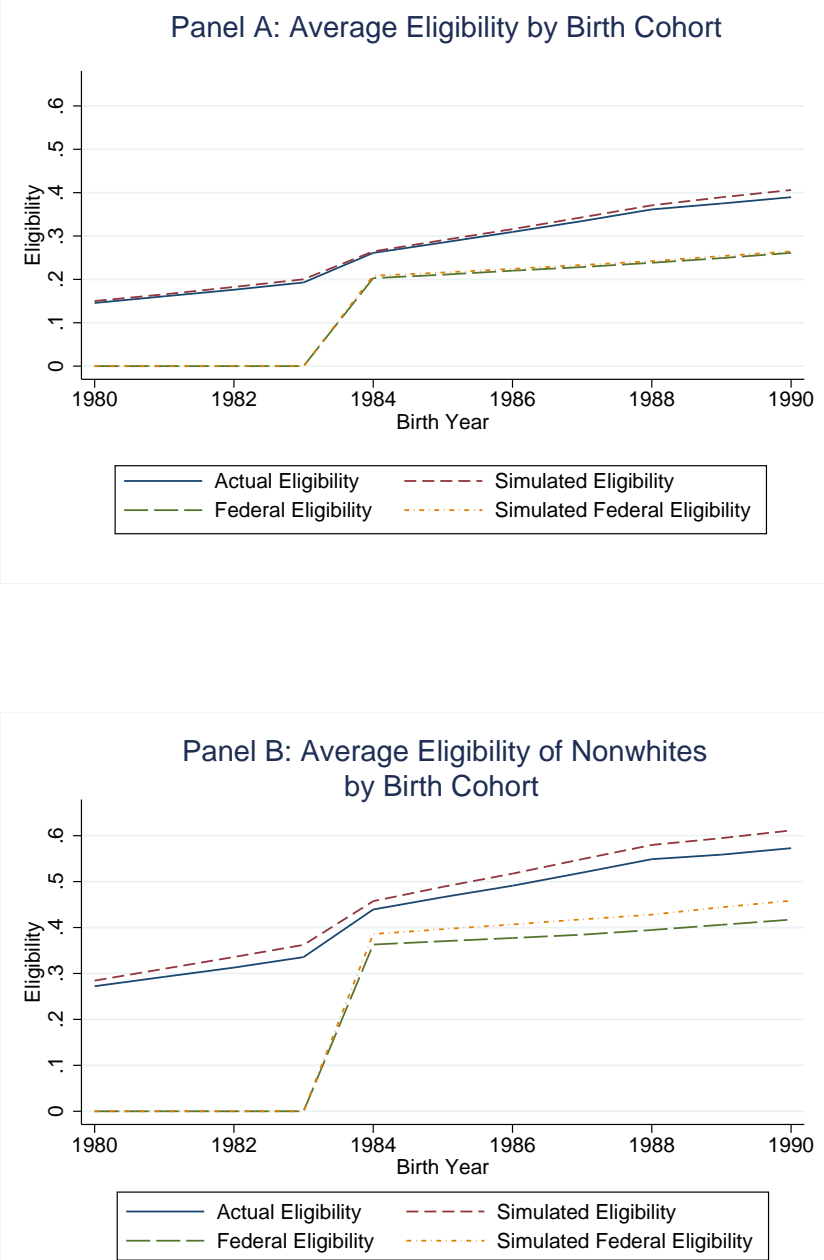

Panel C: Average Eligibility of Whites by Birth Cohort

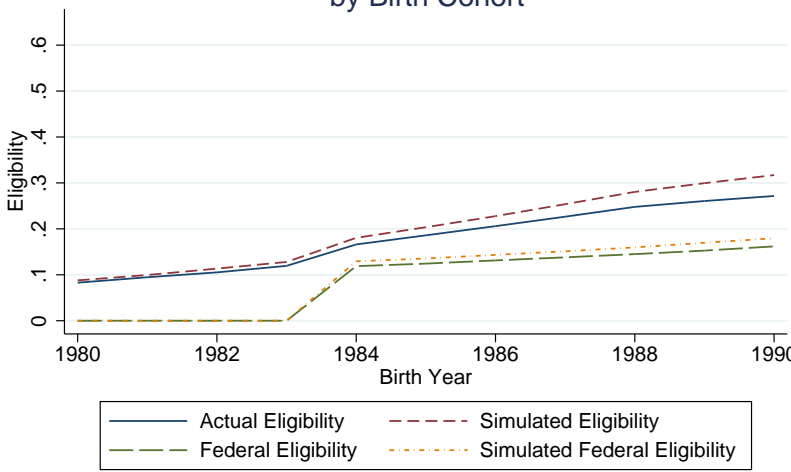

The figure shows average eligibility of 0-17 year olds by birth cohort calculated using 1980-2004 CPS data combined with state by year Medicaid eligibility rules. Eligibility is calculated separately for whites and non-whites. Simulated fixed eligibility is calculated by applying state-by-year rules to 1986 CPS data. Federal eligibility uses only federal Medicaid rules, applied to each state using fixed 1980 AFDC rules. 
Table 1: Birth Cohorts by Age in Each ACS Year

\begin{tabular}{lllllllll}
\hline Age & 2005 & 2006 & 2007 & 2008 & 2009 & 2010 & 2011 & 2012 \\
\hline 22 & 1983 & 1984 & 1985 & 1986 & 1987 & 1988 & 1989 & 1990 \\
23 & 1982 & 1983 & 1984 & 1985 & 1986 & 1987 & 1988 & 1989 \\
24 & 1981 & 1982 & 1983 & 1984 & 1985 & 1986 & 1987 & 1988 \\
25 & 1980 & 1981 & 1982 & 1983 & 1984 & 1985 & 1986 & 1987 \\
26 & & 1980 & 1981 & 1982 & 1983 & 1984 & 1985 & 1986 \\
27 & & & 1980 & 1981 & 1982 & 1983 & 1984 & 1985 \\
28 & & & & 1980 & 1981 & 1982 & 1983 & 1984 \\
29 & & & & & 1980 & 1981 & 1982 & 1983 \\
\hline
\end{tabular}




\section{Table 2: Summary Statistics for Analysis Samples}

\begin{tabular}{lccc}
\hline Variable Name & All & White & Nonwhite \\
\hline No High School & 0.094 & 0.071 & 0.143 \\
No High School or GED & $(0.048)$ & $(0.029)$ & $(0.045)$ \\
& 0.126 & 0.102 & 0.176 \\
At Least Some College & $(0.054)$ & $(0.038)$ & $(0.050)$ \\
& 0.656 & 0.694 & 0.572 \\
College Graduate & $(0.086)$ & $(0.062)$ & $(0.071)$ \\
& 0.265 & 0.309 & 0.172 \\
Age & $(0.108)$ & $(0.096)$ & $(0.065)$ \\
& 25.001 & 25.031 & 24.936 \\
Male & $(2.156)$ & $(2.155)$ & $(2.157)$ \\
& 0.504 & 0.508 & 0.497 \\
White & $(0.039)$ & $(0.032)$ & $(0.049)$ \\
& 0.683 & 1.000 & 0.000 \\
Black & $(0.466)$ & $(0.000)$ & $(0.000)$ \\
& 0.143 & 0.000 & 0.451 \\
Hispanic & $(0.266)$ & $(0.000)$ & $(0.290)$ \\
Other Race & 0.123 & 0.000 & 0.386 \\
& $(0.230)$ & $(0.000)$ & $(0.255)$ \\
Married & 0.052 & 0.000 & 0.163 \\
& $(0.108)$ & $(0.000)$ & $(0.135)$ \\
Age 0-17 3-year Average & 0.616 & 0.671 & 0.496 \\
Medicaid Eligibility & $(0.089)$ & $(0.027)$ & $(0.053)$ \\
Age 0-17 Average Fixed & 0.237 & 0.156 & 0.410 \\
Simulated Medicaid Eligibility & $(0.152)$ & $(0.077)$ & $(0.127)$ \\
Age 0-17 3-year Federal Average & 0.254 & 0.171 & 0.434 \\
Simulated Medicaid Eligibility & 0.113 & $(0.083)$ & $(0.116)$ \\
Age 0-17 Average Federal Fixed & 0.122 & $(0.070)$ & 0.208 \\
Simulated Medicaid Eligibility & $(0.148)$ & 0.074 & $0.195)$ \\
\hline Observations & 5494 & 2754 & $(0.205)$ \\
\hline
\end{tabular}

Source: Author's tabulations from the 2005-2012 ACS. The samples consist of 1980-1990 birth cohorts aged 22-29, for whom we observe Medicaid eligibility in every year in their birth state from age 0 through 17 . All tabulations were done using ACS sample weights. Standard deviations are shown in parentheses. Average eligibility is calculated using 3-year moving averages. The GED tabulations only include ACS years 20082012. Federal Medicaid eligibility is calculated using federal rules only, interacted with 1980 state AFDC rules as described in the text. 
Table 3: The Effect of Average Medicaid Eligibility During School Years on Educational Attainment

\begin{tabular}{|c|c|c|c|c|c|c|c|c|c|c|c|}
\hline \multirow{2}{*}{\multicolumn{2}{|c|}{ Specification }} & \multirow[b]{2}{*}{$1^{\text {st }}$ Stage } & \multicolumn{3}{|c|}{ No HS } & \multicolumn{3}{|c|}{ Some College } & \multicolumn{3}{|c|}{ College Plus } \\
\hline & & & OLS & $\mathrm{RF}$ & IV & OLS & $\mathrm{RF}$ & IV & OLS & $\mathrm{RF}$ & IV \\
\hline \multicolumn{12}{|c|}{ Panel A: All Eligibility } \\
\hline (2) & EITC \& School & $0.951^{* * *}$ & -0.023 & $-0.035^{* *}$ & $-0.037^{* *}$ & 0.024 & 0.028 & 0.029 & 0.017 & $0.062^{* *}$ & $0.065^{* *}$ \\
\hline & Spending & $(0.075)$ & $(0.015)$ & $(0.015)$ & $(0.015)$ & $(0.019)$ & $(0.020)$ & $(0.021)$ & $(0.020)$ & $(0.030)$ & $(0.032)$ \\
\hline (4) & Baseline + & $0.846^{* * *}$ & -0.001 & -0.021 & -0.025 & 0.009 & 0.074 & 0.088 & 0.036 & 0.079 & 0.095 \\
\hline & R-S-Y \& R-A-Y FE & $(0.159)$ & $(0.020)$ & $(0.025)$ & $(0.027)$ & $(0.033)$ & $(0.055)$ & $(0.067)$ & $(0.026)$ & $(0.062)$ & $(0.069)$ \\
\hline \multicolumn{12}{|c|}{ Panel B: Federal Eligibility } \\
\hline$(\overline{5)}$ & Baseline & $0.211^{* * *}$ & $-0.030^{* *}$ & $-0.012^{* * *}$ & $-0.055^{* * *}$ & 0.022 & 0.002 & 0.012 & 0.019 & $0.017^{* * *}$ & $0.079^{* * *}$ \\
\hline
\end{tabular}

Source: Authors' estimation of equation (3) in the text using 22-29 year old respondents from the 2005-2012 ACS. Each cell in the table comes from a separate regression ( $\mathrm{N}=5480)$. The "OLS" columns refer to models that use a three-year moving average of actual eligibility as the dependent variable, and the "RF" columns refer to models that use fixed simulated eligibility as the independent variable. All estimates include an indicator for the cell being nonwhite or not as well as race-by age, race-by-calendar year and race-by-state of birth fixed effects. Rows 3 and 4 include race by state of birth by calendar year (R-S-Y) fixed effects and race by age by calendar year (R-A-Y) fixed effects. Standard errors clustered at the state-of-birth level are in parentheses: $* * *$ indicates significance at the $1 \%$ level, ${ }^{* *}$ indicates significance at the $5 \%$ level, and

* indicates significance at the $10 \%$ level. 
Table 4: The Effect of Average Medicaid Eligibility During School Years on Educational Attainment, Separating GED and HS Diplomas, 2008-2012

\begin{tabular}{|c|c|c|c|c|c|c|c|c|c|c|}
\hline \multirow{2}{*}{\multicolumn{2}{|c|}{ Specification }} & \multirow[b]{2}{*}{$1^{\text {st }}$ Stage } & \multicolumn{2}{|c|}{ No HS Diploma } & \multicolumn{2}{|c|}{ No GED or HS } & \multicolumn{2}{|c|}{ Some College } & \multicolumn{2}{|c|}{ College Plus } \\
\hline & & & OLS & IV & OLS & IV & OLS & IV & OLS & IV \\
\hline \multicolumn{11}{|c|}{ Panel A: All Eligibility } \\
\hline & Baseline & $\begin{array}{c}0.910^{* * *} \\
(0.113)\end{array}$ & $\begin{array}{l}-0.020 \\
(0.019)\end{array}$ & $\begin{array}{c}-0.047^{* *} \\
(0.019)\end{array}$ & $\begin{array}{c}-0.023 \\
(0.020)\end{array}$ & $\begin{array}{c}-0.041^{* *} \\
(0.020)\end{array}$ & $\begin{array}{c}0.009 \\
(0.020)\end{array}$ & $\begin{array}{c}0.043 \\
(0.036)\end{array}$ & $\begin{array}{c}0.025 \\
(0.019)\end{array}$ & $\begin{array}{l}0.081^{*} \\
(0.043)\end{array}$ \\
\hline & EITC \& School & $0.945^{* * *}$ & -0.013 & $-0.047^{* * *}$ & -0.015 & $-0.040^{* *}$ & 0.021 & 0.035 & 0.021 & $0.083^{* *}$ \\
\hline & Spending & $(0.076)$ & $(0.019)$ & $(0.018)$ & $(0.020)$ & $(0.019)$ & $(0.022)$ & $(0.026)$ & $(0.022)$ & $(0.041)$ \\
\hline \multirow[t]{2}{*}{$(3)$} & EITC, School Spending & $0.892^{* * *}$ & 0.011 & -0.025 & 0.004 & -0.015 & 0.032 & $0.071^{*}$ & 0.024 & 0.102 \\
\hline & R-S-Y \& R-A-Y FE & $(0.105)$ & $(0.021)$ & $(0.024)$ & $(0.023)$ & $(0.027)$ & $(0.028)$ & $(0.038)$ & $(0.031)$ & $(0.072)$ \\
\hline \multirow[t]{2}{*}{ (4) } & Baseline + & $0.842^{* * *}$ & 0.009 & -0.028 & 0.003 & -0.021 & -0.003 & 0.090 & 0.019 & 0.092 \\
\hline & R-S-Y \& R-A-Y FE & $(0.160)$ & $(0.020)$ & $(0.026)$ & $(0.023)$ & $(0.028)$ & $(0.030)$ & $(0.067)$ & $(0.026)$ & $(0.076)$ \\
\hline \multicolumn{11}{|c|}{ Panel B: Federal Eligibility } \\
\hline \multirow{2}{*}{\multicolumn{2}{|c|}{ (5) $\quad$ Baseline }} & $0.210^{* * *}$ & -0.020 & $-0.074^{* * *}$ & -0.023 & $-0.074^{* * *}$ & 0.009 & -0.003 & 0.025 & $0.087^{* * *}$ \\
\hline & & $(0.029)$ & $(0.019)$ & $(0.025)$ & $(0.020)$ & $(0.025)$ & $(0.020)$ & $(0.038)$ & $(0.019)$ & $(0.029)$ \\
\hline \multirow[t]{2}{*}{ (6) } & EITC \& School & $0.205^{* * *}$ & -0.013 & $-0.072^{* * *}$ & -0.015 & $-0.072^{* * *}$ & 0.021 & 0.001 & 0.021 & $0.088^{* * *}$ \\
\hline & Spending & $(0.030)$ & $(0.019)$ & $(0.026)$ & $(0.020)$ & $(0.026)$ & $(0.022)$ & $(0.041)$ & $(0.022)$ & $(0.031)$ \\
\hline
\end{tabular}

Source: Authors' estimation of equation (3) in the text using 22-29 year old respondents from the 2008-2012 ACS. Each cell in the table comes from a separate regression $(\mathrm{N}=3957)$. The "OLS" columns refer to models that use a three-year moving average of actual eligibility as the dependent variable, and the "RF" columns refer to models that use fixed simulated eligibility as the independent variable. All estimates include an indicator for the cell being nonwhite or not as well as race-by-age fixed effects, race-by-calendar year fixed effects and race-by-state of birth fixed effects. Rows 3 and 4 include race by state of birth by calendar year (R-S-Y) fixed effects and race by age by calendar year (R-A-Y) fixed effects. Standard errors clustered at the state-of-birth level are in parentheses: *** indicates significance at the $1 \%$ level, ${ }^{* *}$ indicates significance at the $5 \%$ level, and * indicates significance at the $10 \%$ level. 
Table 5: IV Estimatss of the Effect of Average Medicaid Eligibility During School Years on Educational Attainment, by Age at Eligibility

\begin{tabular}{|c|c|c|c|}
\hline Age Range & $\begin{array}{c}\text { No HS } \\
\text { Diploma }\end{array}$ & $\begin{array}{c}\text { Any } \\
\text { College }\end{array}$ & $\begin{array}{l}\text { College } \\
\text { Plus }\end{array}$ \\
\hline \multicolumn{4}{|c|}{ Panel A: Baseline Model } \\
\hline $0-3$ & & $\begin{array}{c}0.017 \\
(0.014)\end{array}$ & $\begin{array}{l}-0.006 \\
(0.007)\end{array}$ \\
\hline $4-8$ & $\begin{array}{c}-0.031^{* *} \\
(0.010)\end{array}$ & $\begin{array}{c}0.012 \\
(0.014)\end{array}$ & \\
\hline $9-13$ & & $\begin{array}{r}-0.0 \\
(0.0\end{array}$ & \\
\hline $14-17$ & $\begin{array}{l}-0.012 \\
(0.009)\end{array}$ & $\begin{array}{l}0.058^{* *} \\
(0.011)\end{array}$ & $\begin{array}{l}0.068^{* *} \\
(0.015)\end{array}$ \\
\hline \multicolumn{4}{|c|}{ Panel B: Baseline + R-S-Y and R-A-Y FE } \\
\hline $0-3$ & $\begin{array}{c}0.000 \\
(0.021)\end{array}$ & $\begin{array}{l}-0.007 \\
(0.031)\end{array}$ & $\begin{array}{c}0.052 \\
(0.038)\end{array}$ \\
\hline $4-8$ & $\begin{array}{l}-0.027 \\
(0.020)\end{array}$ & $\begin{array}{c}0.024 \\
(0.025)\end{array}$ & $\begin{array}{c}0.052 \\
(0.058)\end{array}$ \\
\hline $9-13$ & $\begin{array}{c}0.004 \\
(0.011)\end{array}$ & $\begin{array}{c}0.013 \\
(0.028)\end{array}$ & $\begin{array}{l}-0.002 \\
(0.022)\end{array}$ \\
\hline $14-17$ & $\begin{array}{l}-0.014 \\
(0.015)\end{array}$ & $\begin{array}{l}0.070^{* *} \\
(0.027)\end{array}$ & $\begin{array}{c}0.023 \\
(0.024)\end{array}$ \\
\hline
\end{tabular}

Source: Authors' estimation of equation (3) in the text using 22-29 year old respondents from the 20052012 ACS. Each cell in the table comes from a separate regression $(\mathrm{N}=5480)$. All estimates include an indicator for the cell being nonwhite or not, race-by-age-fixed effects, race-by-calendar year fixed effects and race-by-state of birth fixed effects. Estimates in Panel B also includes race by state of birth by calendar year (R-S-Y) fixed effects and race by age by calendar year (R-A-Y) fixed effects. Standard errors clustered at the state-of-birth level are in parentheses: *** indicates significance at the $1 \%$ level, ** indicates significance at the $5 \%$ level, and * indicates significance at the $10 \%$ level. 
Table 6: The Effect of Average Medicaid Eligibility During School Years on Educational Attainment, Including State of Birth Linear Time Trends Separately by Race

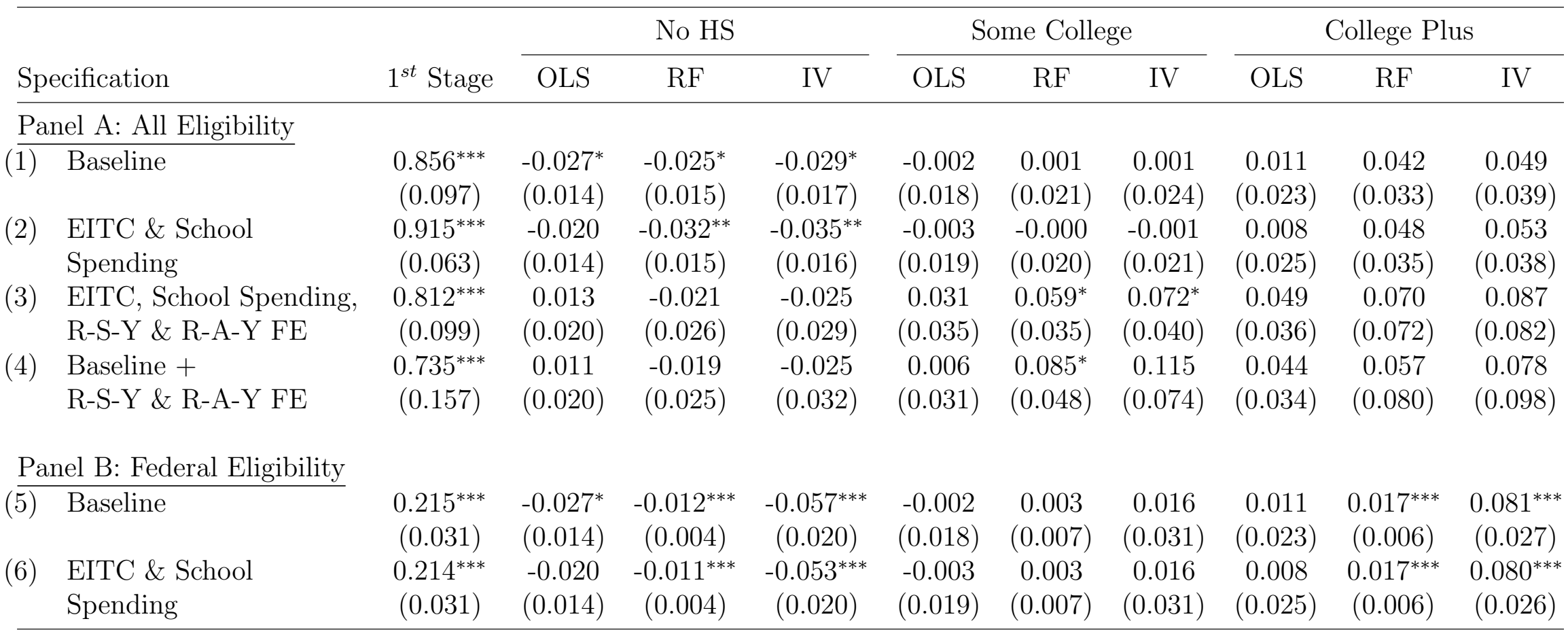

Source: Authors' estimation of equation (3) in the text using 22-29 year old respondents from the 2005-2012 ACS. Each cell in the table comes from a separate regression $(\mathrm{N}=5480)$. The "OLS" columns refer to models that use a three-year moving average of actual eligibility as the dependent variable, and the "IV" columns refer to models that use fixed simulated eligibility as the independent variable. All estimates include an indicator for the cell being nonwhite or not as well as race-by-age fixed effects, race-by-calendar year fixed effects and race-by-state of birth fixed effects. Rows 3 and 4 include race by state of birth by calendar year (R-S-Y) fixed effects and race by age by calendar year (R-A-Y) fixed effects. Estimates also include race by state of birth linear time trends. Standard errors clustered at the state-of-birth level are in parentheses: $* * *$ indicates significance at the $1 \%$ level, $* *$ indicates significance at the $5 \%$ level, and $*$ indicates significance at the $10 \%$ level. 
Table 7: Placebo Test with Randomly Assigned Medicaid Eligibility

\begin{tabular}{|c|c|c|c|c|c|c|}
\hline & \multicolumn{2}{|c|}{ No HS Graduation } & \multicolumn{2}{|c|}{ Some College } & \multicolumn{2}{|c|}{$\mathrm{BA}$} \\
\hline & $\mathrm{RF}$ & IV & $\mathrm{RF}$ & IV & $\mathrm{RF}$ & IV \\
\hline \multirow[t]{2}{*}{ Baseline } & $1.95 \mathrm{e}^{-5}$ & $2.28 \mathrm{e}^{-5}$ & $-3.42 \mathrm{e}^{-5}$ & $-4.54 \mathrm{e}^{-5}$ & -0.0001 & -0.0002 \\
\hline & $(-0.007,0.007)$ & $(-0.008,0.008)$ & $(-0.010,0.011)$ & $(-0.011,0.012)$ & $(-0.009,0.009)$ & $(-0.010,0.010)$ \\
\hline Baseline + & 0.0002 & 0.0002 & $-5.09 \mathrm{e}^{-5}$ & $-8.32 \mathrm{e}^{-5}$ & -0.0003 & -0.0004 \\
\hline R-S-Y \& R-A-Y FE & $(-0.007,0.007)$ & $(-0.008,0.008)$ & $(-0.010,0.011)$ & $(-0.012,0.013)$ & $(-0.010,0.011)$ & $(-0.011,0.012)$ \\
\hline
\end{tabular}

Source: Authors' estimation of equation (3) in the text using 22-29 year old respondents from the 2005-2012 ACS. We randomly assign age-state-year eligibility and fixed simulated eligibility, as a pair, across different age-state-year cells. This is done separately by race. We conduct 500 separate simulations for each outcome, both including and excluding state of birth by calendar year (R-S-Y) fixed effects and race by age by calendar year (R-A-Y) fixed effects. All estimates include an indicator for the cell being non-white or not as well as race-by-age fixed effects, race-by-calendar year fixed effects and race-by-state of birth fixed effects. The table shows the mean estimate across all 500 runs, as well as the $2.5^{t h}$ and $97.5^{t h}$ percentiles in parentheses. The range in parentheses thus show the non-parametric $95 \%$ confidence interval. IV estimates are constructed by dividing the reduced form (RF) by the first stage, which also is estimated using this method. First stage estimates are available upon request from the authors. 
Table 8: The Effect of Average Medicaid Eligibility During School Years on Teen Health Outcomes and Behaviors, Observed Between Ages 14-18

\begin{tabular}{|c|c|c|c|}
\hline Dependent Variable & Mean & OLS & IV \\
\hline Risky Sex Index (0-4) $(\mathrm{n}=1441)$ & 0.962 & $\begin{array}{l}-0.082 \\
(0.209)\end{array}$ & $\begin{array}{c}-0.034 \\
(0.302)\end{array}$ \\
\hline Ever Had Sex $(n=1400)$ & 0.481 & $\begin{array}{c}0.125 \\
(0.102)\end{array}$ & $\begin{array}{c}0.172 \\
(0.181)\end{array}$ \\
\hline Body Mass Index $(\mathrm{n}=1122)$ & 23.210 & $\begin{array}{l}-0.107 \\
(1.006)\end{array}$ & $\begin{array}{l}-0.897 \\
(1.214)\end{array}$ \\
\hline Overweight $(\mathrm{n}=1122)$ & 0.258 & $\begin{array}{l}-0.040 \\
(0.061)\end{array}$ & $\begin{array}{l}-0.163 \\
(0.107)\end{array}$ \\
\hline Obese $(n=1122)$ & 0.086 & $\begin{array}{l}-0.052 \\
(0.071)\end{array}$ & $\begin{array}{l}-0.076 \\
(0.070)\end{array}$ \\
\hline Ever Use Marijuana $(\mathrm{n}=1441)$ & 0.432 & $\begin{array}{l}-0.054 \\
(0.162)\end{array}$ & $\begin{array}{c}-0.174 \\
(0.209)\end{array}$ \\
\hline Number of Days Drank Past Month $(\mathrm{n}=1439)$ & 2.690 & $\begin{array}{l}-0.605 \\
(1.113)\end{array}$ & $\begin{array}{l}-2.832^{*} \\
(1.708)\end{array}$ \\
\hline Ever Smoke Regularly $(\mathrm{n}=1436)$ & 0.197 & $\begin{array}{l}-0.069 \\
(0.113)\end{array}$ & $\begin{array}{l}-0.233 \\
(0.157)\end{array}$ \\
\hline Any Mental Health Issue $(\mathrm{n}=1441)$ & 0.223 & $\begin{array}{c}0.002 \\
(0.124)\end{array}$ & $\begin{array}{l}-0.112 \\
(0.105)\end{array}$ \\
\hline Eating Disorder $(\mathrm{n}=1440)$ & 0.101 & $\begin{array}{c}-0.180^{* * *} \\
(0.059)\end{array}$ & $\begin{array}{r}-0.327^{* * *} \\
(0.077)\end{array}$ \\
\hline
\end{tabular}

Source: Authors' estimation of equation (3) in the text using 14-18 year old respondents from the 19952007 YRBS. Each cell in the table comes from a separate regression. Risky sex index is a count variable that includes ever had sex, no birth control last sexual encounter (a combination of no birth control and condom use variables), ever pregnant, and used alcohol or drugs last sexual encounter. See Appendix Table A-3 for estimates of individual components of the Risky Sex Index as well as the variables from which we calculate whether an individual has a mental health issue or an eating disorder. Medicaid eligibility is calculated as average from age 0 to current age, so for age 14 it is $0-14$. The "OLS" column refers to models that use a three-year moving average of actual eligibility as the independent variable, and the "IV" column refers to models that instrument actual eligibility with fixed simulated eligibility. The first stage coefficient is 0.882 ( $\mathrm{se}=0.123$ ). The estimates include indicators for nonwhite as well as race by age, race by calendar year, and race by state of residence fixed effects. Standard errors clustered at the state-of-residence level are in parentheses: $* * *$ indicates significance at the $1 \%$ level, $* *$ indicates significance at the $5 \%$ level, and * indicates significance at the $10 \%$ level. 
Table A-1: The Effect of Average Medicaid Eligibility During School Years on Educational Attainment using the White Sample

\begin{tabular}{|c|c|c|c|c|c|c|c|c|c|c|c|}
\hline \multirow{2}{*}{\multicolumn{2}{|c|}{ Specification }} & \multirow[b]{2}{*}{$1^{\text {st }}$ Stage } & \multicolumn{3}{|c|}{ No HS } & \multicolumn{3}{|c|}{ Some College } & \multicolumn{3}{|c|}{ College Plus } \\
\hline & & & OLS & $\mathrm{RF}$ & IV & OLS & $\mathrm{RF}$ & IV & OLS & $\mathrm{RF}$ & IV \\
\hline \multicolumn{12}{|c|}{ Panel A: All Eligibility } \\
\hline \multicolumn{2}{|c|}{ (1) $\quad$ Baseline } & $\begin{array}{c}0.706^{* * *} \\
(0.134)\end{array}$ & $\begin{array}{c}-0.022 \\
(0.018)\end{array}$ & $\begin{array}{l}-0.018 \\
(0.023)\end{array}$ & $\begin{array}{l}-0.025 \\
(0.032)\end{array}$ & $\begin{array}{l}-0.005 \\
(0.032)\end{array}$ & $\begin{array}{c}0.014 \\
(0.029)\end{array}$ & $\begin{array}{c}0.019 \\
(0.042)\end{array}$ & $\begin{array}{c}0.020 \\
(0.042)\end{array}$ & $\begin{array}{c}0.051 \\
(0.049)\end{array}$ & $\begin{array}{c}0.073 \\
(0.074)\end{array}$ \\
\hline \multirow[t]{2}{*}{ (2) } & EITC \& School & $0.801^{* * *}$ & -0.012 & -0.030 & -0.037 & -0.003 & 0.013 & 0.016 & 0.020 & 0.061 & 0.076 \\
\hline & Spending & $(0.084)$ & $(0.019)$ & $(0.024)$ & $(0.031)$ & $(0.033)$ & $(0.028)$ & $(0.035)$ & $(0.046)$ & $(0.052)$ & $(0.067)$ \\
\hline \multirow[t]{2}{*}{ (3) } & EITC, School Spending, & $0.745^{* * *}$ & 0.017 & -0.028 & -0.038 & 0.029 & 0.075 & $0.101^{*}$ & 0.102 & 0.098 & 0.132 \\
\hline & S-Y and A-Y FE & $(0.125)$ & $(0.022)$ & $(0.033)$ & $(0.043)$ & $(0.050)$ & $(0.046)$ & $(0.057)$ & $(0.064)$ & $(0.091)$ & $(0.118)$ \\
\hline \multirow[t]{2}{*}{ (4) } & Baseline + & $0.656^{* * *}$ & 0.016 & -0.026 & -0.039 & -0.009 & $0.105^{*}$ & 0.159 & 0.088 & 0.079 & 0.121 \\
\hline & S-Y and A-Y FE & $(0.190)$ & $(0.019)$ & $(0.031)$ & $(0.048)$ & $(0.041)$ & $(0.058)$ & $(0.109)$ & $(0.059)$ & $(0.100)$ & $(0.141)$ \\
\hline \multicolumn{12}{|c|}{ Panel B: Federal Eligibility } \\
\hline \multirow{2}{*}{\multicolumn{2}{|c|}{ (5) $\quad$ Baseline }} & $0.234^{* * *}$ & -0.022 & -0.012 & -0.052 & -0.005 & $0.030^{* *}$ & $0.127^{* *}$ & 0.020 & $0.059^{* * *}$ & $0.250^{* * *}$ \\
\hline & & $(0.027)$ & $(0.018)$ & $(0.010)$ & $(0.040)$ & $(0.032)$ & $(0.015)$ & $(0.061)$ & $(0.042)$ & $(0.015)$ & $(0.066)$ \\
\hline \multirow[t]{2}{*}{ (6) } & EITC \& School & $0.236^{* * *}$ & -0.012 & -0.012 & -0.052 & -0.003 & $0.031^{* *}$ & $0.129^{* *}$ & 0.020 & $0.060^{* * *}$ & $0.253^{* * *}$ \\
\hline & Spending & $(0.028)$ & $(0.019)$ & $(0.010)$ & $(0.040)$ & $(0.033)$ & $(0.015)$ & $(0.062)$ & $(0.046)$ & $(0.015)$ & $(0.069)$ \\
\hline
\end{tabular}

Source: Authors' estimation of equation (3) in the text using 22-29 year old white respondents from the 2005-2012 ACS. Each cell in the table comes from a separate regression $(\mathrm{N}=2754)$. The "OLS" columns refer to models that use a three-year moving average of actual eligibility as the dependent variable, and the "RF" columns refer to models that use fixed simulated eligibility as the independent variable. All estimates include age fixed effects, calendar year fixed effects and state of birth fixed effects. Rows 3 and 4 include state of birth by calendar year (S-Y) fixed effects and age by calendar year (A-Y) fixed effects. Standard errors clustered at the state-of-birth level are in parentheses: ${ }^{* * *}$ indicates significance at the $1 \%$ level, ${ }^{* *}$ indicates significance at the $5 \%$ level, and * indicates significance at the $10 \%$ level. 
Table A-2: The Effect of Average Medicaid Eligibility During School Years on Educational Attainment using the Nonwhite Sample

\begin{tabular}{|c|c|c|c|c|c|c|c|c|c|c|c|}
\hline \multirow{2}{*}{\multicolumn{2}{|c|}{ Specification }} & \multirow[b]{2}{*}{$1^{\text {st }}$ Stage } & \multicolumn{3}{|c|}{ No HS } & \multicolumn{3}{|c|}{ Some College } & \multicolumn{3}{|c|}{ College Plus } \\
\hline & & & OLS & $\mathrm{RF}$ & IV & OLS & $\mathrm{RF}$ & IV & OLS & $\mathrm{RF}$ & IV \\
\hline \multicolumn{12}{|c|}{ Panel A: All Eligibility } \\
\hline & Baseline & $\begin{array}{c}1.128^{* * *} \\
(0.137)\end{array}$ & $\begin{array}{c}-0.035^{*} \\
(0.019)\end{array}$ & $\begin{array}{c}-0.053^{* *} \\
(0.023)\end{array}$ & $\begin{array}{c}-0.047^{* *} \\
(0.020)\end{array}$ & $\begin{array}{c}0.039 \\
(0.025)\end{array}$ & $\begin{array}{c}0.042 \\
(0.031)\end{array}$ & $\begin{array}{c}0.036 \\
(0.027)\end{array}$ & $\begin{array}{c}0.019 \\
(0.014)\end{array}$ & $\begin{array}{c}0.059^{* * *} \\
(0.019)\end{array}$ & $\begin{array}{r}0.053^{* * *} \\
(0.019)\end{array}$ \\
\hline$(2)$ & EITC \& School & $1.095^{* * *}$ & $-0.035^{*}$ & $-0.050^{* *}$ & $-0.045^{* *}$ & 0.041 & 0.040 & 0.036 & 0.012 & $0.057^{* * *}$ & $0.052^{* * *}$ \\
\hline & Spending & $(0.100)$ & $(0.019)$ & $(0.022)$ & $(0.019)$ & $(0.027)$ & $(0.034)$ & $(0.030)$ & $(0.016)$ & $(0.020)$ & $(0.019)$ \\
\hline (3) & EITC, School Spending, & $1.059^{* * *}$ & -0.012 & -0.011 & -0.011 & 0.058 & 0.051 & 0.050 & 0.001 & $0.090^{*}$ & $0.087^{*}$ \\
\hline & S-Y \& A-Y FE & $(0.182)$ & $(0.031)$ & $(0.046)$ & $(0.039)$ & $(0.045)$ & $(0.083)$ & $(0.069)$ & $(0.032)$ & $(0.048)$ & $(0.050)$ \\
\hline (4) & Baseline + & $1.101^{* * *}$ & -0.013 & -0.015 & -0.014 & 0.022 & 0.033 & 0.032 & -0.000 & 0.079 & 0.074 \\
\hline & S-Y \& A-Y FE & $(0.256)$ & $(0.030)$ & $(0.049)$ & $(0.039)$ & $(0.051)$ & $(0.087)$ & $(0.071)$ & $(0.029)$ & $(0.053)$ & $(0.056)$ \\
\hline \multicolumn{12}{|c|}{ Panel B: Federal Eligibility } \\
\hline$(\overline{5)}$ & Baseline & $0.206^{* * *}$ & $-0.035^{*}$ & $-0.012^{* *}$ & $-0.056^{* *}$ & 0.039 & -0.004 & -0.018 & 0.019 & 0.007 & 0.034 \\
\hline & & $(0.032)$ & $(0.019)$ & $(0.005)$ & $(0.027)$ & $(0.025)$ & $(0.008)$ & $(0.036)$ & $(0.014)$ & $(0.007)$ & $(0.031)$ \\
\hline (6) & EITC \& School & $0.200^{* * *}$ & $-0.035^{*}$ & $-0.012^{* *}$ & $-0.059^{* *}$ & 0.041 & -0.004 & -0.021 & 0.012 & 0.006 & 0.031 \\
\hline & Spending & $(0.033)$ & $(0.019)$ & $(0.005)$ & $(0.029)$ & $(0.027)$ & $(0.008)$ & $(0.038)$ & $(0.016)$ & $(0.007)$ & $(0.033)$ \\
\hline
\end{tabular}

Source: Authors' estimation of equation (3) in the text using 22-29 year old non-white respondents from the 2005-2012 ACS. Each cell in the table comes from a separate regression $(\mathrm{N}=2726)$. The "OLS" columns refer to models that use a three-year moving average of actual eligibility as the dependent variable, and the "RF" columns refer to models that use fixed simulated eligibility as the independent variable. All estimates include age fixed effects, calendar year fixed effects and state of birth fixed effects. Rows 3 and 4 include state of birth by calendar year (S-Y) fixed effects and age by calendar year (A-Y) fixed effects. Standard errors clustered at the state-of-birth level are in parentheses: ${ }^{* * *}$ indicates significance at the $1 \%$ level, ${ }^{* *}$ indicates significance at the $5 \%$ level, and * indicates significance at the $10 \%$ level. 
Table A-3: The Effect of Average Medicaid Eligibility During School Years on Teen Health Outcomes and Behaviors, Observed Between Ages 14-18

\begin{tabular}{|c|c|c|c|}
\hline Dependent Variable & Mean & OLS & IV \\
\hline Risky Sex Index (0-4) $(\mathrm{n}=1441)$ & 0.962 & $\begin{array}{l}-0.082 \\
(0.209)\end{array}$ & $\begin{array}{l}-0.034 \\
(0.302)\end{array}$ \\
\hline Ever Had Sex $(n=1400)$ & 0.481 & $\begin{array}{c}0.125 \\
(0.102)\end{array}$ & $\begin{array}{c}0.172 \\
(0.181)\end{array}$ \\
\hline No Birth Control $(\mathrm{n}=1338)$ & 0.230 & $\begin{array}{l}-0.080 \\
(0.166)\end{array}$ & $\begin{array}{l}-0.214 \\
(0.210)\end{array}$ \\
\hline Used Condom Last Encounter $(\mathrm{n}=1338)$ & 0.633 & $\begin{array}{c}0.222 \\
(0.180)\end{array}$ & $\begin{array}{c}0.217 \\
(0.188)\end{array}$ \\
\hline Ever Pregnant or Impregnate Partner $(\mathrm{n}=1057)$ & 0.051 & $\begin{array}{c}0.063 \\
(0.051)\end{array}$ & $\begin{array}{c}0.072 \\
(0.073)\end{array}$ \\
\hline Used Drugs or Alcohol Last Sexual Encounter $(\mathrm{n}=1339)$ & 0.243 & $\begin{array}{l}-0.091 \\
(0.146)\end{array}$ & $\begin{array}{l}-0.114 \\
(0.211)\end{array}$ \\
\hline Any Mental Health Issue $(\mathrm{n}=1441)$ & 0.223 & $\begin{array}{c}0.002 \\
(0.124)\end{array}$ & $\begin{array}{l}-0.112 \\
(0.105)\end{array}$ \\
\hline Considered Suicide $(\mathrm{n}=1441)$ & 0.186 & $\begin{array}{l}-0.008 \\
(0.120)\end{array}$ & $\begin{array}{l}-0.049 \\
(0.105)\end{array}$ \\
\hline Planned Suicide $(\mathrm{n}=1441)$ & 0.149 & $\begin{array}{c}0.021 \\
(0.120)\end{array}$ & $\begin{array}{l}-0.102 \\
(0.127)\end{array}$ \\
\hline Attempted Suicide $(\mathrm{n}=1438)$ & 0.084 & $\begin{array}{l}-0.033 \\
(0.067)\end{array}$ & $\begin{array}{l}-0.154^{*} \\
(0.083)\end{array}$ \\
\hline Hurt Self Attempting Suicide $(\mathrm{n}=1438)$ & 0.026 & $\begin{array}{l}-0.047 \\
(0.033)\end{array}$ & $\begin{array}{r}-0.131^{* * *} \\
(0.048)\end{array}$ \\
\hline Number of Suicide Attempts ( $\mathrm{n}=1438)$ & 0.180 & $\begin{array}{l}-0.103 \\
(0.160)\end{array}$ & $\begin{array}{c}-0.449^{* *} \\
(0.228)\end{array}$ \\
\hline Eating Disorder $(\mathrm{n}=1440)$ & 0.101 & $\begin{array}{c}-0.180^{* * *} \\
(0.059)\end{array}$ & $\begin{array}{c}-0.327^{* * *} \\
(0.077)\end{array}$ \\
\hline Bulimic $(\mathrm{n}=1440)$ & 0.050 & $\begin{array}{c}-0.091^{* *} \\
(0.044)\end{array}$ & $\begin{array}{c}-0.163^{* *} \\
(0.064)\end{array}$ \\
\hline Used Diet Pills $(\mathrm{n}=1440)$ & 0.074 & $\begin{array}{c}-0.129^{* * *} \\
(0.044)\end{array}$ & $\begin{array}{c}-0.205^{* * *} \\
(0.052)\end{array}$ \\
\hline
\end{tabular}

Source: Authors' estimation of equation (3) in the text using 14-18 year old respondents from the 19952007 YRBS. Each cell in the table comes from a separate regression, and the indented variables make up the index listed above them. Any mental health issue is coded as 1 if an individual reports any of the suicide ideation variables included in the table. Any eating disorder includes both bulimia and diet pill use. Medicaid eligibility is calculated as average from age 0 to current age, so for age 14 it is 0-14. The "OLS" column refers to models that use a three-year moving average of actual eligibility as the independent variable, and the "IV" column refers to models that instrument actual eligibility with fixed simulated eligibility. The first stage coefficient is $0.882(\mathrm{se}=0.123)$. The estimates include indicators for nonwhite as well as race by age, race by calendar year, and race by state of residence fixed effects. Standard errors clustered at the state-of-residence level are in parentheses: $* * *$ indicates significance at the $1 \%$ level, $* *$ indicates significance at the $5 \%$ level, and * indicates significance at the $10 \%$ level. 